\title{
Combination strategies with PD-1/PD- L1 blockade: current advances and future directions
}

Ming $\mathrm{Yi}^{1 \dagger}$, Xiaoli Zheng ${ }^{2 \dagger}$, Mengke Niu', Shuangli Zhu ${ }^{1}$, Hong $\mathrm{Ge}^{2^{*}}$ and Kongming $\mathrm{Wu}^{1,2^{*}}$ (D)

\begin{abstract}
Antibodies targeting programmed cell death protein-1 (PD-1) or its ligand PD-L1 rescue T cells from exhausted status and revive immune response against cancer cells. Based on the immense success in clinical trials, ten a-PD-1 (nivolumab, pembrolizumab, cemiplimab, sintilimab, camrelizumab, toripalimab, tislelizumab, zimberelimab, prolgolimab, and dostarlimab) and three a-PD-L1 antibodies (atezolizumab, durvalumab, and avelumab) have been approved for various types of cancers. Nevertheless, the low response rate of a-PD-1/PD-L1 therapy remains to be resolved. For most cancer patients, PD-1/PD-L1 pathway is not the sole speed-limiting factor of antitumor immunity, and it is insufficient to motivate effective antitumor immune response by blocking PD-1/PD-L1 axis. It has been validated that some combination therapies, including a-PD-1/PD-L1 plus chemotherapy, radiotherapy, angiogenesis inhibitors, targeted therapy, other immune checkpoint inhibitors, agonists of the co-stimulatory molecule, stimulator of interferon genes agonists, fecal microbiota transplantation, epigenetic modulators, or metabolic modulators, have superior antitumor efficacies and higher response rates. Moreover, bifunctional or bispecific antibodies containing a-PD-1/PD-L1 moiety also elicited more potent antitumor activity. These combination strategies simultaneously boost multiple processes in cancer-immunity cycle, remove immunosuppressive brakes, and orchestrate an immunosupportive tumor microenvironment. In this review, we summarized the synergistic antitumor efficacies and mechanisms of a-PD-1/PD-L1 in combination with other therapies. Moreover, we focused on the advances of a-PD-1/PD-L1-based immunomodulatory strategies in clinical studies. Given the heterogeneity across patients and cancer types, individualized combination selection could improve the effects of a-PD-1/PD-L1-based immunomodulatory strategies and relieve treatment resistance.
\end{abstract}

Keywords: PD-1, PD-L1, Combination therapy, Angiogenesis inhibitor, Radiotherapy, STING, Gut microbiota, Bispecific antibody

*Correspondence: zlyygehong0199@zzu.edu.cn; kmwu@tjh.tjmu.edu.cn ${ }^{\dagger}$ Ming Yi and Xiaoli Zheng contributed equally to this work.

1 Department of Oncology, Tongji Hospital of Tongji Medical College, Huazhong University of Science and Technology, Wuhan 430030, China

${ }^{2}$ Department of Radiation Oncology, The Affiliated Cancer Hospital of Zhengzhou University \& Henan Cancer Hospital, Zhengzhou 450008, China

\section{Background}

Programmed cell death 1 (PD-1) signaling is commonly hijacked by cancer cells to escape immune surveillance [1]. When PD-1 and T cell receptor (TCR) bind to their ligands, the immunoreceptor tyrosine-based inhibitory motif and immunoreceptor tyrosine-based switch motif of PD-1 are phosphorylated [2]. Subsequently, Src homology region 2 domain-containing phosphatase (SHP-2) is recruited and activated, reversing the phosphorylation of downstream signaling of TCR and CD28 [3, 4]. Besides 
inhibiting some early activating pathways of T cells, PD-1 directly undermines antigen recognition by disrupting the trimolecular interaction of TCR-pMHC-CD8 [5]. As a result, PD-1 signaling suppresses $\mathrm{T}$ cell functions, including activation, proliferation, and cytokine production [6]. At present, antibodies blocking PD-1 or its ligand PD-L1 have been approved to treat various solid and hematologic malignancies (Table 1) [7-12]. Although $\alpha-P D-1 / P D-L 1$ therapies exhibit potent antitumor effects in some patients, most patients could not benefit from $\alpha-\mathrm{PD}-1 / \mathrm{PD}-\mathrm{L} 1$ treatments, owing to primary or acquired treatment resistance [13]. For the non-responders, PD-1 signaling is not the speed-limiting rheostat of cancerimmunity cycle, and it is insufficient to revive antitumor immunity by blocking PD-1 or PD-L1 [14].

Apart from PD-1 signaling, other immune checkpoints, abnormal angiogenesis, immunosuppressive immune cells or cytokines, cancer-associated adipocytes, and hyperactive cancer-associated fibroblasts also modulate cancer-immune set point and promote immune tolerance [15-20]. Logically, removing these negative factors could enhance the therapeutic effect of $\alpha$-PD-1/PD-L1 and relieve drug resistance. On the other hand, some positive factors such as immunogenic cancer cell death, immunosupportive cytokines, and professional antigen presentation cells (pAPCs) contribute to immune clearance [21]. Correspondingly, strengthening these positive elements might boost the cancer-immune cycle, drive the transformation from cold to hot tumors, and improve the response to $\alpha$-PD-1/PD-L1 therapies [21].

The combination strategy is deemed as a rational and feasible approach to achieve optimal treatment effects. Accumulating evidence indicates that chemotherapy, radiotherapy, angiogenesis inhibitor, stimulator of interferon genes (STING) agonist, fecal microbiota transplantation (FMT), epigenetic modulators, or other immunomodulators could synergize $\alpha-P D-1 / P D-L 1$, by enhancing cancer antigen release, APC function, or effector activity [22-31]. In this review, we summarized the synergistic effects of combination immunotherapies and the underlying mechanisms. Moreover, given the development of antibody technology, we also introduced the emerging bispecific or bifunctional antibodies targeting PD-1 or PD-L1.

Table 1 The approved indications of a-PD-1/PD-L1 antibodies in the globe

\begin{tabular}{|c|c|c|c|c|c|c|c|c|c|c|c|c|c|c|c|c|c|c|}
\hline Drugs & Approval & SC & NSCLC & SCLC & RCC & $\mathrm{HL}$ & HNC & UC & CRC & $\mathrm{HCC}$ & ESC & MPM & GC & GEJC & TNBC & BC & $\mathrm{CC}$ & $\overline{E C}$ \\
\hline Nivolumab & $\begin{array}{l}\text { 2014-US } \\
2015-E U \\
2018-P R C\end{array}$ & $\sqrt{ }$ & $\sqrt{ }$ & $\sqrt{ }$ & $\sqrt{ }$ & $\sqrt{ }$ & $\sqrt{ }$ & $\sqrt{ }$ & $\sqrt{ }$ & $\sqrt{ }$ & $\sqrt{ }$ & $\sqrt{ }$ & $\sqrt{ }$ & $\sqrt{ }$ & - & - & - & - \\
\hline Pembrolizumab & $\begin{array}{l}\text { 2014-US } \\
\text { 2015-EU } \\
\text { 2018-PRC }\end{array}$ & $\sqrt{ }$ & $\sqrt{ }$ & $\sqrt{ }$ & $\sqrt{ }$ & $\sqrt{ }$ & $\sqrt{ }$ & $\sqrt{ }$ & $\sqrt{ }$ & $\sqrt{ }$ & $\sqrt{ }$ & - & $\sqrt{ }$ & $\sqrt{ }$ & $\sqrt{ }$ & $\sqrt{ }$ & $\sqrt{ }$ & $\sqrt{ }$ \\
\hline Cemiplimab & $\begin{array}{l}\text { 2018-US } \\
\text { 2019-EU }\end{array}$ & $\sqrt{ }$ & $\sqrt{ }$ & - & - & - & - & - & - & - & - & - & - & - & - & - & - & - \\
\hline Toripalimab & 2018-PRC & $\sqrt{ }$ & - & - & - & - & $\sqrt{ }$ & $\sqrt{ }$ & - & - & - & - & - & - & - & - & - & - \\
\hline Sintilimab & 2018-PRC & - & $\sqrt{ }$ & - & - & $\sqrt{ }$ & - & - & - & $\sqrt{ }$ & - & - & - & - & - & - & - & - \\
\hline Camrelizumab & 2019-PRC & - & $\sqrt{ }$ & - & - & $\sqrt{ }$ & $\sqrt{ }$ & - & - & $\sqrt{ }$ & $\sqrt{ }$ & - & - & - & - & - & - & - \\
\hline Tislelizumab & 2019-PRC & - & $\sqrt{ }$ & - & - & $\sqrt{ }$ & - & $\sqrt{ }$ & - & - & - & - & - & - & - & - & - & - \\
\hline Zimberelimab & 2021-PRC & - & - & - & - & $\sqrt{ }$ & - & - & - & - & - & - & - & - & - & - & - & - \\
\hline Prolgolimab & 2020-RU & $\sqrt{ }$ & - & - & - & - & - & - & - & - & - & - & - & - & - & - & - & - \\
\hline Dostarlimab & $\begin{array}{l}\text { 2021-US } \\
\text { 2021-EU }\end{array}$ & - & - & - & - & - & - & - & - & - & - & - & - & - & - & - & - & $\sqrt{ }$ \\
\hline Atezolizumab & $\begin{array}{l}\text { 2016-US } \\
2017-E U \\
2020-P R C\end{array}$ & $\sqrt{ }$ & $\sqrt{ }$ & $\sqrt{ }$ & - & - & - & $\sqrt{ }$ & - & $\sqrt{ }$ & - & - & - & - & $\sqrt{ }$ & - & - & - \\
\hline Durvalumab & $\begin{array}{l}\text { 2017-US } \\
\text { 2018-EU } \\
\text { 2019-PRC }\end{array}$ & - & $\sqrt{ }$ & $\sqrt{ }$ & - & - & - & - & - & - & - & - & - & - & - & $\sqrt{ }$ & - & - \\
\hline Avelumab & $\begin{array}{l}\text { 2017-US } \\
\text { 2017-EU }\end{array}$ & $\sqrt{ }$ & - & - & $\sqrt{ }$ & - & - & $\sqrt{ }$ & - & - & - & - & - & - & - & - & - & - \\
\hline
\end{tabular}

Abbreviations: SC skin cancer, NSCLC non-small cell lung cancer, $R C C$ renal cell carcinoma, HL Hodgkin lymphoma, HNC head and neck cancer, UC urothelial carcinoma, $C R C$ colorectal cancer, HCC hepatocellular carcinoma, ESC esophageal carcinoma, MPM malignant pleural mesothelioma, GC gastric cancer, GEJC gastroesophageal junction cancer, TNBC triple-negative breast cancer, BC bladder cancer, CC cervical cancer, EC endometrial cancer, EU European Union, PRC People's Republic of China. $\sqrt{ }$ denotes the indication approved in the globe 


\section{Conventional chemotherapy combined with a-PD-1/PD-L1}

\section{Chemotherapy modifying the TME}

Chemotherapy retards tumor growth mainly by arresting cell cycle, inhibiting DNA replication, disturbing cell metabolism, or suppressing microtubule assembly [32]. Besides, some cytotoxic chemotherapeutic drugs such as anthracycline and oxaliplatin could induce immunogenic cell death and stimulate antitumor immune response [33, 34]. Immunogenic cell death is featured with some upregulated damage-associated molecular patterns (DAMPs) such as the secretion of IFN-I, the exposure of endoplasmic reticulum proteins especially calreticulin (CRT, an eat-me signal) on cell membrane, the leak of ATP (a findme signal), and the release of high-mobility group box 1 (HMGB1) [35]. The receptors of CRT, ATP, and HMGB1 are CD91, P2RX7, TLR4 on dendritic cells (DCs). The ATP-P2RX7 signaling recruits DCs into the tumor bed; the CRT-CD91 axis promotes DC to engulf cancer antigens; the HMGB1-TLR4 pathway facilitates the optimal cancer antigen presentation [36]. Collectively, the antigen capture and presentation of DC are enhanced, ultimately motivating adaptive antitumor immune response (Fig. 1a).

Apart from immunogenic cell death, chemotherapy could directly eliminate immune suppressor cells and enhance the functions of effector cells, especially administrated at the dose below maximumtolerated dose [37]. Low-dose cyclophosphamide depleted circulating and tumor-infiltrating regulatory T cells (Tregs) [38-40]. Moreover, paclitaxel promoted tumor-associated macrophage (TAM) to repolarize from M2-like to M1-like phenotype [41]. Notably, although 5-fluorouracil, doxorubicin, gemcitabine, and docetaxel reduced circulating myeloid-derived suppressor cells (MDSCs) in mouse models [42-45], some chemotherapeutic agents increased circulating MDSCs in cancer patients [46]. Therefore, the chemotherapymediated MDSC depletion remains further verification in cancer patients. Besides suppressor cells, some certain chemotherapies such as cyclophosphamide, gemcitabine, and vinblastine recruited and activated DC in the immunogenic cell death manner [47-49]. Also, chemotherapeutic drugs such as vinblastine, 5-fluorouracil, and oxaliplatin, could directly enhance the functions of DC and promote IL-12 secretion [49, 50]. Additionally, pemetrexed enhanced the activation of tumor-infiltrating lymphocytes (TILs) by improving mitochondrial biogenesis, independent of immunogenic cell death [51].

\section{Chemotherapy combined with a-PD-1}

Based on the immune-modulatory effect of chemotherapeutic agents, chemotherapy might be an appropriate partner with $\alpha$-PD-1/PD-L1 to achieve both rapid and long-term cancer control. Nowadays, chemotherapy combined with $\alpha$-PD-1/PD-L1 has become a standardof-care option for some cancer patients, and there are hundreds of ongoing clinical trials exploring the efficacy and safety of chemotherapy plus $\alpha-P D-1 / P D-L 1$ (Table 2). In the clinical trial KEYNOTE-021 (phase 2), nonsquamous non-small cell lung cancer (NSCLC) patients receiving pembrolizumab combined with standard chemotherapy (carboplatin and pemetrexed) had a higher response rate and longer progression-free survival (PFS) than did patients receiving standard chemotherapy [52]. Based on the results of KEYNOTE-021, pembrolizumab plus chemotherapy has been approved by the FDA as the first-line treatment for advanced non-squamous NSCLC, regardless of PD-L1 level [52]. Later, in two phase 3 clinical studies (KEYNOTE-189 and KEYNOTE-407), pembrolizumab combined with standard chemotherapy led to a better overall survival (OS) and PFS in NSCLC patients, relative to chemotherapy monotherapy [53, 54]. The results of KEYNOTE-407 engaged the FDA to approve pembrolizumab combined with chemotherapy for squamous NSCLC in 2018. Then, based on a string of successes (KEYNOTE-355, KEYNOTE-590, and KEYNOTE-811), the indication of pembrolizumab plus

\footnotetext{
(See figure on next page.)

Fig. 1 The synergistic antitumor efficacies and mechanisms of a-PD-1/PD-L1 in combination with chemotherapy, radiotherapy, or angiogenesis inhibitor. a Chemotherapy synergizes with a-PD-1/PD-L1. Some cytotoxic chemotherapeutic drugs could induce immunogenic cell death and stimulate antitumor immune response. Immunogenic cell death is featured with some upregulated damage-associated molecular patterns (DAMPs) such as calreticulin (CRT), ATP, and high-mobility group box 1 (HMGB1). The ATP-P2RX7, CRT-CD91, and HMGB1-TLR4 pathways facilitate the antigen capture and presentation of DC, ultimately motivating adaptive antitumor immune response. Apart from immunogenic cell death, low-dose chemotherapy depletes regulatory T cells (Tregs) and promotes the repolarization of tumor-associated macrophage (TAM) from M2-like to M1-like phenotype. b Radiotherapy synergizes with a-PD-1/PD-L1. Firstly, radiotherapy could induce immunogenic cell death, enhance antitumor immune response, promote T cell infiltration, expand T-cell receptor (TCR) repertoire in the TME. Secondly, radiotherapy upregulates the expression of PD-L1 on tumor cells, which might be utilized by additional a-PD-1/PD-L1. Thirdly, radiotherapy increases the MHC-I on tumor cells and relieves resistance to a-PD-1/PD-L1. c Angiogenesis inhibitor synergizes with a-PD-1/PD-L1. Angiogenesis inhibitor blocks proangiogenic pathways, promotes vessel normalization, improves tumor perfusion and oxygenation, restores the hypoxic TME, and enhances drug delivery. Also, angiogenesis inhibitor reshapes the TME: promoting T cell infiltration and DC maturation, enhancing the differentiation towards M1-like macrophage, decreasing the ratio of Treg and MDSC, and alleviating hypoxia-induced PD-L1
} 


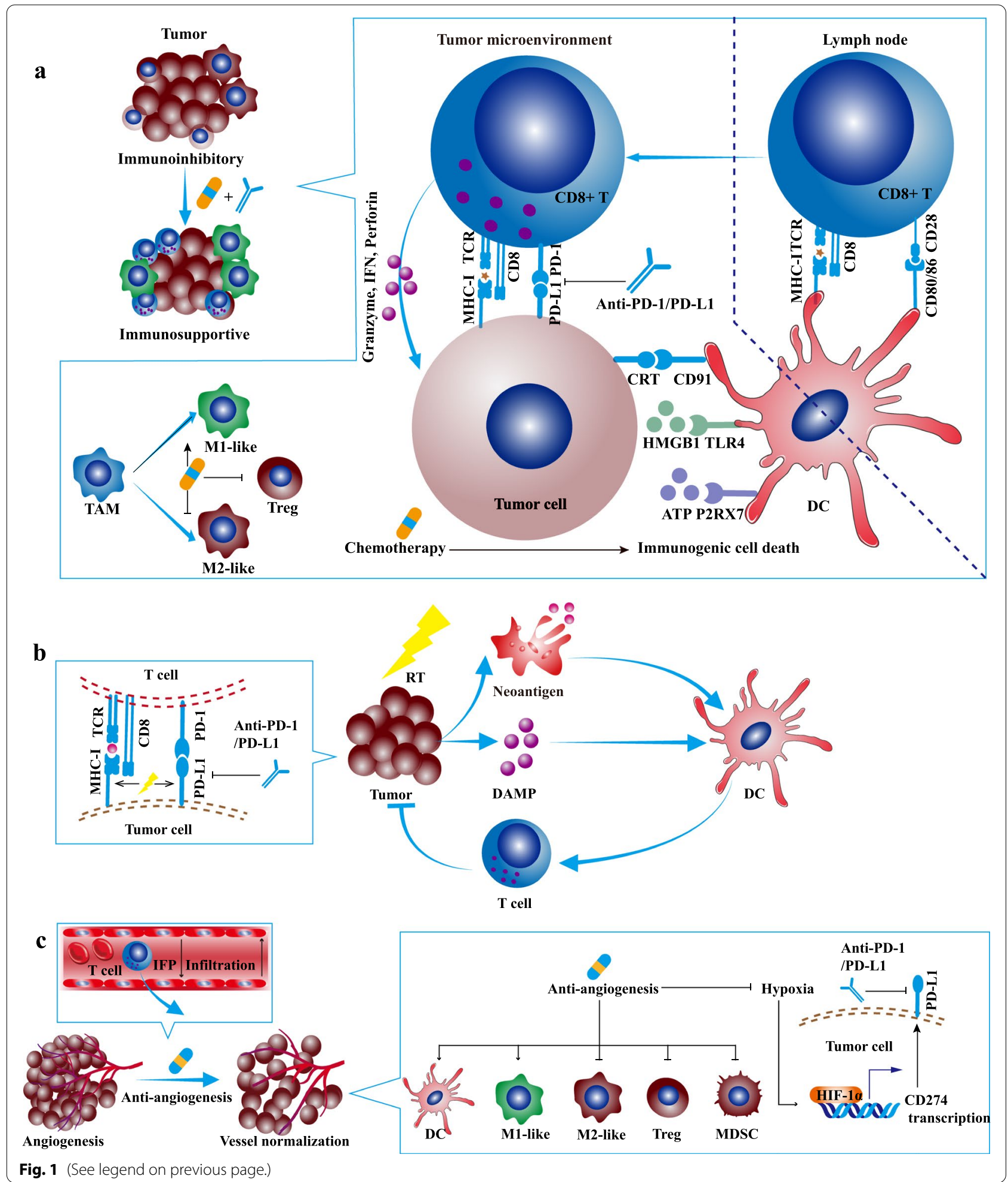

chemotherapy was expanded to advanced triple-negative breast cancer (TNBC), esophageal cancer, gastroesophageal junction cancer (GEJC) [55-57].
Generally, pembrolizumab has a great advantage on chemoimmunotherapy, with a broad range of indications. The FDA rarely approves chemoimmunotherapeutic 
Table 2 The clinical trials exploring the efficacy of a-PD-1/PD-L1 plus chemotherapy

\begin{tabular}{|c|c|c|c|c|c|}
\hline Clinical trial & Phase & a-PD-1/PD-L1 & Chemotherapy & Cancer type & $\begin{array}{l}\text { Primary } \\
\text { outcome } \\
\text { measures }\end{array}$ \\
\hline NCT02039674 & $1 / 2$ & Pembrolizumab & Pemetrexed and carboplatin & Non-squamous NSCLC & ORR \\
\hline NCT02775435 & 3 & Pembrolizumab & Paclitaxel/nab-paclitaxel and carboplatin & Squamous NSCLC & PFS, OS \\
\hline NCT02819518 & 3 & Pembrolizumab & $\begin{array}{l}\text { Paclitaxel; nab-paclitaxel; } \\
\text { gemcitabine and carboplatin }\end{array}$ & TNBC & PFS, OS \\
\hline NCT03189719 & 3 & Pembrolizumab & Cisplatin and 5-fluorouracil & Esophageal or GEJ cancer & PFS, OS \\
\hline NCT03615326 & 3 & Pembrolizumab & $\begin{array}{l}\text { Trastuzumab plus either 5-fluorouracil plus } \\
\text { cisplatin or capecitabine plus oxaliplatin }\end{array}$ & HER2 + gastric or GEJ adenocarcinoma & PFS, OS \\
\hline NCT02872116 & 3 & Nivolumab & $\begin{array}{l}\text { 5-fluorouracil and leucovorin plus oxaliplatin; } \\
\text { capecitabine and oxaliplatin }\end{array}$ & $\begin{array}{l}\text { Gastric cancer, esophageal or GEJ adenocar- } \\
\text { cinoma }\end{array}$ & PFS, OS \\
\hline NCT03607539 & 3 & Sintilimab & Pemetrexed and platinum & Non-squamous NSCLC & PFS \\
\hline NCT03629925 & 3 & Sintilimab & Gemcitabine and platinum & Squamous NSCLC & PFS \\
\hline NCT03134872 & 3 & Camrelizumab & Carboplatin and pemetrexed & Non-squamous NSCLC & PFS \\
\hline NCT03707509 & 3 & Camrelizumab & Gemcitabine and cisplatin & Nasopharyngeal carcinoma & PFS \\
\hline NCT03594747 & 3 & Tislelizumab & Paclitaxel/nab-paclitaxel and carboplatin & Squamous NSCLC & PFS \\
\hline NCT03663205 & 3 & Tislelizumab & Platinum and pemetrexed & Non-squamous NSCLC & PFS \\
\hline NCT02366143 & 3 & Atezolizumab & Bevacizumab plus paclitaxel and carboplatin & Non-squamous NSCLC & PFS, OS \\
\hline NCT02763579 & 3 & Atezolizumab & Carboplatin and etoposide & SCLC & PFS, OS \\
\hline NCT02425891 & 3 & Atezolizumab & Nab-paclitaxel & TNBC & PFS, OS \\
\hline NCT02367781 & 3 & Atezolizumab & Carboplatin and nab-paclitaxel & Non-squamous NSCLC & PFS, OS \\
\hline NCT03043872 & 3 & Durvalumab & Etoposide and carboplatin/ cisplatin & SCLC & OS \\
\hline
\end{tabular}

Abbreviations: NSCLC non-small cell lung cancer, ORR objective response rate, PFS progression-free survival, OS overall survival, GEJ gastroesophageal junction, SCLC small cell lung cancer

strategies with other $\alpha$-PD-1 drugs (except for nivolumab combined with chemotherapy for gastric cancer and GEJC) [58]. In China, the NMPA approved sintilimab plus pemetrexed and platinum as the first-line treatment for advanced non-squamous NSCLC, based on the results of ORIENT-11 [59]. In addition, the NMPA approved sintilimab plus gemcitabine and platinum as the first-line treatment for advanced squamous NSCLC, based on the results of ORIENT-12 [60]. In 2020, the NMPA also approved camrelizumab plus carboplatin and pemetrexed as the first-line treatment for non-squamous NSCLC, based on the results of CameL [61]. Later in 2021, the NMPA approved camrelizumab plus gemcitabine and cisplatin (for advanced nasopharyngeal carcinoma) and tislelizumab plus chemotherapy (for NSCLC) [62-64].

\section{Chemotherapy combined with a-PD-L1}

Besides $\alpha$-PD-1, $\alpha$-PD-L1-based chemoimmunotherapy also attracts intensive attention, especially chemoimmunotherapeutic regimens with atezolizumab. IMpower150 is the pioneer of this series of studies, assessing the efficacy of atezolizumab plus angiogenesis inhibitor and chemotherapy in advanced non-squamous NSCLC [65]. Based on the results of IMpower150, the FDA approved atezolizumab plus bevacizumab, paclitaxel, and carboplatin as the first-line treatment for advanced nonsquamous NSCLC [65]. Subsequently, the FDA approved atezolizumab plus chemotherapy for TNBC (atezolizumab plus nab-paclitaxel, based on IMpassion130), SCLC (atezolizumab plus carboplatin and etoposide, based on IMpower133), and non-squamous NSCLC (atezolizumab plus nab-paclitaxel and carboplatin, based on IMpower130) [66-68]. Moreover, based on the results of CASPIAN, durvalumab combined with platinum plus etoposide therapy was approved for SCLC in the US [69]. Presently, there are still dozens of chemoimmunotherapeutic regimens with $\alpha$-PD-1/PD-L1 awaiting approval in the US and China.

\section{Radiotherapy combined with a-PD-1/PD-L1 The mechanisms by which radiotherapy synergizing a-PD-1/PD-L1}

Like some chemotherapeutic drugs, radiotherapy could induce immunogenic cell death and enhance antitumor immune response [70]. On the one hand, immunogenic cell death-associated DAMPs and cytokines especially IFN-I recruit immune cells and promote the function of DCs. On the other hand, released tumor antigens could be captured by DCs and presented to T cells [70]. Consequently, radiotherapy not only eliminates local lesions but also stimulates the systemic antitumor immune 
response (also known as abscopal effects) [71]. Previous preclinical and clinical studies demonstrated that radiotherapy could synergize $\alpha$-PD-1/PD-L1 in multiple manners. Firstly, radiotherapy promoted $\mathrm{T}$ cell infiltration, increased the number of TILs, and expanded T-cell receptor (TCR) repertoire in the TME [72, 73]. Secondly, radiotherapy upregulated the expression of $\mathrm{PD}-\mathrm{L} 1$ on tumor cells, which can be utilized by additional $\alpha-\mathrm{PD}-1 /$ PD-L1 [74]. Thirdly, radiotherapy increased the MHC-I on tumor cells and relieved resistance to $\alpha-\mathrm{PD}-1 / \mathrm{PD}-\mathrm{L} 1$ (Fig. 1b) [75]. However, some problems have not been well addressed, including the fractionation, dose, schedule of radiotherapy, irradiated tumor volume, irradiated regional lymph nodes, and the schedule of $\alpha-\mathrm{PD}-1 /$ PD-L1 post-radiotherapy [76].

\section{Clinical studies exploring the efficacy and safety of radiotherapy combined with a-PD-1/PD-L1}

Most radioimmunotherapy regimens are based on stereotactic body radiotherapy (SBRT), which could precisely deliver ablative doses of radiation in image-guided and intensity-modulated manners [77]. The results of the phase 1 study NCT02608385 demonstrated that $\alpha-P D-1 / P D-L 1$ combined with SBRT was well-tolerable (Table 3) [24]. Moreover, the results of some phase $1 / 2$ studies (NCT02621398, NCT02434081, NCT02586207, NCT02383212, and NCT02402920) showed that $\alpha-P D-1 / P D-L 1$ plus chemoradiotherapy was tolerable in advanced NSCLC, head and neck squamous cell carcinoma (HNSCC), and SCLC patients, with promising clinical outcomes [78-82].

In the phase 2 study NCT02904954, SBRT combined with durvalumab acquired a superior antitumor effect to durvalumab in early-stage NSCLC [83]. In the combination therapy arm, patients received 24Gy SBRT before durvalumab treatment (given in three consecutive daily fractions of $8 \mathrm{~Gy}$ ) [83]. The major pathological response rate was significantly higher in the SBRT combined with durvalumab arm than that in the durvalumab arm [83]. Additionally, the results of the phase 3 study NCT02125461 indicated that sequential durvalumab treatment markedly improved the PFS and OS of NSCLC patients undergoing chemoradiotherapy [84]. However, in the phase 2 study NCT02684253, SBRT combined with nivolumab was not superior to nivolumab in response rate, PFS, and OS in advanced HNSCC [85]. Furthermore, in the phase 3 study NCT02952586 exploring the efficacy of avelumab plus standard-of-care chemoradiotherapy in HNSCC, it did not meet the primary endpoint (PFS) [86]. Considering the multiple variants in the combination therapy such as dose, volume, fractionation, sequence, more efforts are needed to explore optimal radioimmunotherapy schemes.

\section{Angiogenesis inhibitor combined with a-PD-1/ PD-L1}

Abnormal angiogenesis hampering the antitumor immune response

Hyperactive metabolism and incommensurate blood supply contribute to the hypoxic and acid TME [87]. As the feedback on hypoxia, the levels of some pro-angiogenic cytokines such as vascular endothelial growth factor (VEGF) and angiopoietin 2 (ANGPT2) are upregulated, driving angiogenesis [88]. The disorganized angiogenesis promotes the formation of the immunosuppressive TME [16]. Firstly, the immature and leaky vessels lead to increased interstitial fluid pressure, which hinders blood perfusion and immune cell infiltration [89]. Secondly, VEGF could inhibit the maturation of DC, induce the exhaustion of $\mathrm{T}$ cells, promote the proliferation of Tregs,

Table 3 The clinical trials exploring the efficacy of a-PD-1/PD-L1 plus radiotherapy

\begin{tabular}{|c|c|c|c|c|c|}
\hline Clinical trial & Phase & a-PD-1/PD-L1 & Radiotherapy & Cancer type & Primary outcome measures \\
\hline NCT02608385 & 1 & Pembrolizumab & SBRT & Solid tumors & Recommended SBRT dose \\
\hline NCT02621398 & 1 & Pembrolizumab & Concurrent chemoradiation & NSCLC & MTD and DLT \\
\hline NCT02434081 & 2 & Nivolumab & Concurrent chemoradiation & NSCLC & Safety \\
\hline NCT02586207 & 1 & Pembrolizumab & Concurrent chemoradiation & HNSCC & Safety \\
\hline NCT02383212 & 1 & Cemiplimab & Concurrent chemoradiation & Solid tumors & Safety, DLT \\
\hline NCT02402920 & 1 & Pembrolizumab & $\begin{array}{l}\text { Concurrent chemoradiation; } \\
\text { Concurrent radiation }\end{array}$ & $\mathrm{SCLC}$ & $\mathrm{DLT}$ \\
\hline NCT02904954 & 2 & Durvalumab & SBRT & NSCLC & Pathological response rate \\
\hline NCT02125461 & 3 & Durvalumab & Concurrent chemoradiation & NSCLC & PFS, OS \\
\hline NCT02684253 & 2 & Nivolumab & SBRT & HNSCC & $\mathrm{BOR}$ \\
\hline NCT02952586 & 3 & Avelumab & Concurrent chemoradiation & HNSCC & PFS \\
\hline
\end{tabular}

Abbreviations: SBRT stereotactic body radiotherapy, NSCLC non-small cell lung cancer, MDT maximum tolerated dose, DLT dose limiting toxicity, PFS progression-free survival, OS overall survival, SCLC small cell lung cancer, HNSCC head and neck squamous cell carcinoma, BOR best overall response 
and increase the ratio of MDSCs [90-93]. Thirdly, despite without direct influence on T cells, ANGPT2 recruits Tie-2-expressing monocytes, enhances the differentiation towards M2-like macrophages, and upregulates the expression of IL-10 [94-97]. Moreover, other proangiogenic cytokines such as placental growth factor (PLGF) and TGF- $\beta$ also contribute to immunosuppression [98].

\section{Angiogenesis inhibitor synergizing with a-PD-1/PD-L1}

Commonly, the transformation from nascent to functional vessel needs maturational processes, which are disturbed by hyperactive angiogenesis in the TME [99]. Angiogenesis inhibitor blocks these proangiogenic pathways, promotes vessel normalization, improves tumor perfusion and oxygenation, restores the hypoxic TME, and enhances drug delivery $[100,101]$. Also, angiogenesis inhibitor reshapes the TME: promoting $\mathrm{T}$ cell infiltration and DC maturation, enhancing the differentiation towards M1-like macrophage, decreasing the ratio of Treg and MDSC, and alleviating hypoxia-induced PD-L1 (Fig. 1c) [93, 102-105]. In the multiple preclinical studies, angiogenesis inhibitor enhanced the efficacy of $\alpha-\mathrm{PD}-1 /$ PD-L1 in murine tumor models [106-108].

In 2019, pembrolizumab combined with axitinib was approved by the FDA as the first-line treatment for advanced RCC, based on the results of KEYNOTE-426 (Table 4) [109]. At a median follow-up time of 30.6 months, the median OS and PFS were longer in the pembrolizumab combined with axitinib arm compared to those in the sunitinib arm [109]. Moreover, pembrolizumab plus lenvatinib was also approved for advanced endometrial carcinoma [110]. Additionally, as mentioned above, the FDA approved atezolizumab plus bevacizumab and chemotherapy as the first-line treatment for advanced non-squamous NSCLC based on the results of IMpower150 [65]. Then, in 2020, the FDA approved atezolizumab combined with bevacizumab for advanced HCC based on the data of IMbrave150 [111]. Besides pembrolizumab plus axitinib, nivolumab plus cabozantinib (based on CheckMate-9ER) [112] and avelumab plus axitinib (based on JAVELIN Renal 101) [113] were also approved by the FDA as the initial-line treatment for RCC.

Up to now, most angiogenesis inhibitor plus $\alpha-\mathrm{PD}-1 /$ PD-L1 strategies are undergoing clinical trials, having not been approved by the FDA or NMPA. Combination therapies such as sintilimab plus anlotinib, sintilimab plus IBI305 (bevacizumab biosimilar), camrelizumab plus apatinib, and toripalimab plus axitinib demonstrated potent antitumor effects in multiple types of cancers [22, 114-120]. Despite encouraging results, further phase 3 trials are needed to validate the efficacies of these combination regimens.

\section{Dual immune checkpoint blockade or co-stimulatory molecule agonist plus a-PD-1/ PD-L1 \\ a-CTLA-4 plus a-PD-1/PD-L1}

CTLA-4 is primarily expressed on activated T cells and Tregs, as a negative regulator for $\mathrm{T}$ cell activation [121].

Table 4 The clinical trials exploring the efficacy of a-PD-1/PD-L1 combined with angiogenesis inhibitor

\begin{tabular}{|c|c|c|c|c|c|}
\hline Clinical trial & Phase & a-PD-1/PD-L1 & Angiogenesis inhibitor & Cancer type & $\begin{array}{l}\text { Primary } \\
\text { outcome } \\
\text { measures }\end{array}$ \\
\hline NCT02853331 & 3 & Pembrolizumab & Axitinib & $\mathrm{RCC}$ & PFS, OS \\
\hline NCT02501096 & $1 \mathrm{~b} / 2$ & Pembrolizumab & Lenvatinib & Solid tumors & MTD, ORR, DLT \\
\hline NCT03517449 & 3 & Pembrolizumab & Lenvatinib & Endometrial cancer & PFS, OS \\
\hline NCT02366143 & 3 & Atezolizumab & Bevacizumab plus chemotherapy & Non-Squamous NSCLC & PFS, OS \\
\hline NCT03434379 & 3 & Atezolizumab & Bevacizumab & $\mathrm{HCC}$ & PFS, OS \\
\hline NCT03141177 & 3 & Nivolumab & Cabozantinib & $\mathrm{RCC}$ & PFS \\
\hline NCT02684006 & 3 & Avelumab & Axitinib & $\mathrm{RCC}$ & PFS, OS \\
\hline NCT03628521 & $1 b$ & Sintilimab & Anlotinib & NSCLC & Safety, ORR \\
\hline NCT03794440 & $2 / 3$ & Sintilimab & IBI305 & $\mathrm{HCC}$ & PFS, OS \\
\hline NCT02942329 & $1 / 2$ & Camrelizumab & Apatinib & Gastric cancer, HCC & OS rate \\
\hline NCT03417895 & 2 & Camrelizumab & Apatinib & $\mathrm{SCLC}$ & Safety, ORR \\
\hline NCT03816553 & 2 & Camrelizumab & Apatinib & Cervical cancer & ORR \\
\hline NCT03394287 & 2 & Camrelizumab & Apatinib & TNBC & ORR \\
\hline NCT03359018 & 2 & Camrelizumab & Apatinib & Osteosarcoma & PFS, CBR \\
\hline NCT03086174 & 1 & Toripalimab & Axitinib & Kidney cancer, melanoma & Safety \\
\hline
\end{tabular}

Abbreviations: NSCLC non-small cell lung cancer, MDT maximum tolerated dose, DLT dose limiting toxicity, PFS progression-free survival, OS overall survival, SCLC small cell lung cancer, NSCLC non-small cell lung cancer, RCC renal cell carcinoma, TNBC triple-negative breast cancer, $H C C$ hepatocellular carcinoma, $C B R$ clinical benefit rate 
On the one hand, CTLA-4 could competitively suppress the binding of $\mathrm{CD} 28$ to $\mathrm{CD} 80 / \mathrm{CD} 86$, halting the secondary signal of $\mathrm{T}$ cell activation [122]. On the other hand, CTLA-4 engagement with CD80/CD86 counteracts TCR-induced downstream signaling and suppresses PI3K-Akt pathway (vital signaling of $\mathrm{T}$ cell activation), via SHP-2 and protein phosphatase 2A (PP2A) [123, 124]. Additionally, CTLA-4 could capture, remove, and degrade its ligands CD80/CD86 from nearby APCs by trans-endocytosis, further hampering the co-stimulatory signal [125]. It is commonly believed that CTLA-4 signaling mainly undermines $\mathrm{T}$ cell priming in secondary lymphoid organs [126]. Ipilimumab (developed by Bristol-Myers Squibb) is the first approved $\alpha$-CTLA-4 drug, initially used for advanced melanoma [127]. So far, the mechanism of antitumor activity of ipilimumab is still unclear. Theoretically, ipilimumab blocks the binding of CTLA-4 to CD80/CD86, removes the immunoinhibitory signal, and promotes $\mathrm{T}$ cell priming. However, multiple studies have been confirmed that antibody-dependent cell-mediated cytotoxicity of Treg also substantially contributes to the antitumor activity of ipilimumab [128-130].

In the clinic, ipilimumab is rarely used alone. Instead, ipilimumab is commonly used in combination with nivolumab. Although both CTLA-4 and PD-1 are immune checkpoints, they inhibit $\mathrm{T}$ cell activation in nonredundant manners. Therefore, $\alpha$-CTLA- 4 might cooperate with $\alpha$-PD-1/PD-L1 to boost the antitumor immune response. Accumulating evidence has indicated that dual PD-1/PD-L1 and CTLA-4 blockade has superior antitumor activity in some types of cancers [131]. The results of CheckMate-069, CheckMate-067, and CheckMate-142 showed that ipilimumab plus nivolumab significantly improved the outcomes of patients, relative to ipilimumab or nivolumab monotherapies [132-134]. Moreover, the data of CheckMate-214, CheckMate-227, and CheckMate-743 indicated the superior efficacy of ipilimumab plus nivolumab over the standard targeted therapy or chemotherapy [135-137]. Until now, the FDA has approved the ipilimumab plus nivolumab for melanoma, RCC, MSI-H/dMMR colorectal cancer, HCC, PD-L1 positive NSCLC, and malignant pleural mesothelioma (Table 5) [132-138].

Tremelimumab is a human IgG2 monoclonal antibody (developed by AstraZeneca) targeting CTLA4 , which has entered phase 3 clinical trials [139]. The efficacy of tremelimumab plus durvalumab has been intensively investigated in SCLC, urothelial carcinoma, colorectal cancer, HNSCC, NSCLC, gastric and GEJ adenocarcinoma, germ cell tumors, mesothelioma, pancreatic ductal adenocarcinoma, and HCC $[69,140-152]$. The results of some clinical trials were unsatisfactory, and no additional benefit was brought by tremelimumab plus durvalumab, compared to durvalumab monotherapy or standard chemotherapy [140, 142, 144]. However, the subgroup analysis showed that tremelimumab plus durvalumab markedly improved the OS of NSCLC patients with a high tumor mutation burden [145], indicating the importance of appropriate patient selection for the optimal benefit of tremelimumab plus durvalumab.

Apart from efficacy, it is concerned that dual PD-1/ PD-L1 and CTLA-4 blockade might lead to serious immune-related adverse events (irAEs) such as colitis, hypophysitis, pneumonitis, and thyroiditis [153]. Therefore, ipilimumab is commonly administrated at a reduced dose [154], which might weaken the efficacy of combination therapy. A preclinical study found that prophylactic TNF blockade could dissociate the efficacy and toxicity of $\alpha$-CTLA- 4 plus $\alpha-P D-1 / P D-L 1$ therapy [155]. Further clinical investigations are needed to improve the safety and strengthen the efficacy of dual PD-1/PD-L1 and CTLA-4 blockade.

\section{a-PD-1/PD-L1 plus other ICls}

Other dual immune checkpoint blockade strategies, including $\alpha$-PD-1/PD-L1 combined with $\alpha$-TIM-3, $\alpha$-LAG-3, $\alpha$-PVRIG, $\alpha$-TIGIT, are still in clinical trials, having not been approved by the FDA or NMPA. The engagement of TIM-3 with its ligand galectin-9 led to Th1 cell death by triggering intracellular calcium flux [156]. Dual blockade of TIM-3 and PD-1/PD-L1 dramatically enhanced antitumor immune response and retarded tumor growth in murine tumor models [157]. The results of clinical trials showed that $\alpha$-TIM- 3 plus $\alpha-\mathrm{PD}-1 / \mathrm{PD}-\mathrm{L} 1$ was tolerable without unexpected safety signals, but more efforts are needed for patient selection [158-160].

Besides $\alpha$-TIM-3, other ICIs such as $\alpha$-LAG-3, $\alpha$-PVRIG, $\alpha$-TIGIT, $\alpha$ - Siglec-10 also synergized with $\alpha-P D-1 / P D-L 1$ in enhancing TIL function and suppressing tumor growth [161-164]. In the phase $2 / 3$ study RELATIVITY-047, relatlimab ( $\alpha$-LAG-3) plus nivolumab therapy demonstrated a significant PFS benefit (10.1 vs. 4.6 months, HR: 0.75 ) in advanced melanoma, relatively to nivolumab monotherapy [165]. Moreover, in the phase 1 study NCT03667716, COM701 ( $\alpha$-PVRIG) plus nivolumab exhibited encouraging antitumor activity even in some patients with prior ICI treatment [166]. In addition, in the phase 2 study NCT03563716, tiragolumab $(\alpha$-TIGIT) plus atezolizumab showed an improvement in ORR (OR:2.57, 95\%CI:1.07-6.14) and PFS (HR:0.57; 95\%CI $0.37-0.90)$ in PD-L1 positive NSCLC, relative to placebo plus atezolizumab [167]. 
Table 5 The clinical trials exploring the efficacy of dual immune checkpoint blockade or immune checkpoint agonist plus a-PD-1/ PD-L1

\begin{tabular}{|c|c|c|c|c|c|}
\hline Clinical trial & Phase & a-PD-1/PD-L1 & $\begin{array}{l}\text { Other immune checkpoint } \\
\text { inhibitors (Target) }\end{array}$ & Cancer type & Primary outcome measures \\
\hline NCT01844505 & 3 & Nivolumab & Ipilimumab (CTLA-4) & Melanoma & PFS, OS, PFS rate, OS rate \\
\hline NCT01927419 & 2 & Nivolumab & Ipilimumab (CTLA-4) & Melanoma & ORR \\
\hline NCT02060188 & 2 & Nivolumab & Ipilimumab (CTLA-4) & Colorectal cancer & ORR \\
\hline NCT02231749 & 3 & Nivolumab & Ipilimumab (CTLA-4) & $\mathrm{RCC}$ & ORR, PFS, OS \\
\hline NCT02477826 & 3 & Nivolumab & Ipilimumab (CTLA-4) & NSCLC & PFS, OS \\
\hline NCT02899299 & 3 & Nivolumab & Ipilimumab (CTLA-4) & Mesothelioma & OS \\
\hline NCT03043872 & 3 & Durvalumab & $\begin{array}{l}\text { Tremelimumab (CTLA-4) plus chemo- } \\
\text { therapy }\end{array}$ & $\mathrm{SCLC}$ & OS \\
\hline NCT02812420 & 1 & Durvalumab & Tremelimumab (CTLA-4) & Urothelial cancer & Safety \\
\hline NCT02516241 & 3 & Durvalumab & Tremelimumab (CTLA-4) & Urothelial cancer & OS \\
\hline NCT02870920 & 2 & Durvalumab & Tremelimumab (CTLA-4) & Colorectal cancer & OS \\
\hline NCT02369874 & 3 & Durvalumab & Tremelimumab (CTLA-4) & HNSCC & OS \\
\hline NCT02453282 & 3 & Durvalumab & Tremelimumab (CTLA-4) & NSCLC & OS, PFS \\
\hline NCT02352948 & 2 & Durvalumab & Tremelimumab (CTLA-4) & NSCLC & OS, PFS \\
\hline NCT02340975 & $1 / 2$ & Durvalumab & Tremelimumab (CTLA-4) & Gastric or GEJ adenocarcinoma & Safety, ORR, PFS rate \\
\hline NCT02319044 & 2 & Durvalumab & Tremelimumab (CTLA-4) & HNSCC & ORR \\
\hline NCT03081923 & 2 & Durvalumab & Tremelimumab (CTLA-4) & Germ cell tumors & ORR \\
\hline NCT02588131 & 2 & Durvalumab & Tremelimumab (CTLA-4) & Mesothelioma & ORR \\
\hline NCT02519348 & $1 / 2$ & Durvalumab & Tremelimumab (CTLA-4) & $\mathrm{HCC}$ & Safety \\
\hline NCT02558894 & 2 & Durvalumab & Tremelimumab (CTLA-4) & Pancreatic ductal adenocarcinoma & ORR \\
\hline NCT03099109 & 1 & LY3300054 & LY3321367 (TIM-3) & Solid tumor & Safety \\
\hline NCT02791334 & 1 & LY3300054 & LY3321367 (TIM-3) & Solid tumor & Safety \\
\hline NCT02608268 & $1 / 2$ & Spartalizumab & Sabatolimab (TIM-3) & Solid tumor & Safety, ORR \\
\hline NCT03470922 & $2 / 3$ & Nivolumab & Relatlimab (LAG-3) & Melanoma & PFS \\
\hline NCT03667716 & 1 & Nivolumab & COM701 (PVRIG) & Solid tumor & Safety \\
\hline NCT03563716 & 2 & Atezolizumab & Tiragolumab (TIGIT) & NSCLC & ORR, PFS \\
\hline NCT02179918 & 1 & Pembrolizumab & PF-05082566 (4-1BB) & Solid tumor & Safety \\
\hline NCT03502330 & 1 & Nivolumab & APX005M (CD40) & Melanoma, NSCLC, RCC & Safety \\
\hline NCT03829501 & $1 / 2$ & Atezolizumab & KY1044 (ICOS) & Solid tumor & Safety, ORR \\
\hline NCT02740270 & 1 & Spartalizumab & GWN323 (GITR) & Solid tumor, lymphomas & Safety \\
\hline
\end{tabular}

Abbreviations: NSCLC non-small cell lung cancer, PFS progression-free survival, OS overall survival, SCLC small cell lung cancer, NSCLC non-small cell lung cancer, RCC renal cell carcinoma, HCC hepatocellular carcinoma, GEJ gastroesophageal junction, HNSCC head and neck squamous cell carcinoma

\section{Co-stimulatory molecule agonist plus a-PD-1/PD-L1}

Besides co-inhibitory pathways such as PD-1 and CTLA4, co-stimulatory pathways including CD27/CD70, CD40/CD40L, 4-1BB/4-1BBL, OX40/OX40L, GITR/ GITRL, and ICOS/ICOSL also regulate $\mathrm{T}$ cell function (Fig. 2a) [168]. Agonists targeting co-stimulatory pathways could enhance $\mathrm{T}$ cell activity and revolve antitumor immune response [169]. A series of preclinical studies showed that co-stimulatory molecule agonists improved $\alpha-P D-1 / P D-L 1$ efficacy [170-176]. At present, multiple clinical studies of co-stimulatory molecule agonists plus $\alpha-\mathrm{PD}-1 / \mathrm{PD}-\mathrm{L} 1$ are ongoing. The preliminary data showed that these combination strategies were well-tolerated, supporting further investigation in advanced solid tumors [177-180].

\section{Targeted therapy (except for angiogenesis inhibitor) combined with a-PD-1/PD-L1}

Epidermal growth factor receptor-tyrosine kinase inhibitor (EGFR-TKI) plus a-PD-1/PD-L1

EGFR is a member of ErbB family driving the initiation and development of multiple types of cancers [181]. Upon the engagement with its ligands (such as epidermal growth factor, transforming growth factor-alpha, amphiregulin), EGFR would be homodimerized or heterodimerized [182]. Then, the cytoplasmic tyrosine kinases domain of EGFR is phosphorylated, triggering the activation of PI3K-AKT and MAPK pathways [182]. Some cancers especially NSCLC are addicted to the hyperactive EGFR pathway [183]. Therefore, agents targeting EGFR could effectively suppress the growth of these 
EGFR-addictive cancers. Generally believed, the efficacy of $\alpha$-PD-1/PD-L1 is modest in EGFR-mutated patients $[184,185]$, which might be attributed to the lack of concurrent TIL and PD-L1 expression, low tumor mutation burden, or increased Tregs in the TME [186]. Recent studies demonstrated that EGFR-TKI could promote $\mathrm{T}$ cell infiltration, decrease the ratios of tumor-infiltrating Treg and M2-like macrophage, and improve the responsiveness to $\alpha$-PD-1/PD-L1 in EGFR-mutated models [17, 187]. Besides, activated EGFR signaling contributes to the upregulated PD-L1 on cancer cells, and EGFR-TKI might cooperate with $\alpha-\mathrm{PD}-1 / \mathrm{PD}-\mathrm{L} 1$ to attenuate immune evasion [188]. Collectively, EGFR-TKI plus $\alpha$-PD-1/PD-L1 therapy would maximize the efficacy of immunotherapy in patients with EGFR-mutated cancers (Fig. 2b).

In the phase 1 trial CheckMate-012, nivolumab combined with erlotinib showed potent and durable antitumor activity in EGFR-mutated NSCLC patients, with tolerable adverse events (no grade 4/5 adverse event reported) (Table 6) [189]. Moreover, in the phase 1 study NCT02013219, EGFR-mutated NSCLC patients received erlotinib (150 mg QD for 7 days), followed by erlotinib (150 mg QD) plus $1200 \mathrm{mg}$ atezolizumab (1200 mg, q3w) [190]. The ORR of combination therapy was as high as $75 \%$ in the expansion-stage group, and tumor-infiltrating CD8+ $\mathrm{T}$ cell was increased in 8/13 paired biopsies after 7-day erlotinib treatment [190]. No pneumonitis and dose-limiting toxicity were reported in this study [190]. However, a retrospective study found that patients receiving nivolumab plus erlotinib might have a higher risk of treatment-associated interstitial pneumonitis (Odds ratio: 4.31, $P<0.001$ ), relative to patients undergoing EGFR-TKI monotherapy [191]. Additionally, in the phase 1 study TATTON, the incidence rate of interstitial lung disease in the osimertinib (a third-generation EGFR-TKI) plus durvalumab arm was unexpectedly high (22\%), leading to the termination of patient enrollment [192]. Because of the increased risk of treatment-associated interstitial lung disease, a phase 3 clinical trial CAURAL was stopped early [193]. Although the mechanisms of combination therapy-caused irAEs are still unclear, it has been confirmed that treatment sequence and timing are closely associated with the incidence of irAE. PD-1/ PD-L1 blockade followed by osimertinib led to a higher incidence rate of irAE, while osimertinib followed by PD-1/PD-L1 blockade decreased the risk of irAE [194]. This phenomenon appears to be unique to osimertinib [194]. The efficacy and toxicity of EGFR-TKI plus $\alpha$-PD-1/PD-L1 should be further valuated in patients harboring EGFR-mutations.

\section{Anaplastic lymphoma kinase (ALK)-TKI plus a-PD-1/PD-L1}

ALK is a receptor tyrosine kinase belonging to insulin receptor superfamily [195]. EML4-ALK fusion is the most common ALK arrangement variant in NSCLC patients [196]. The constitutively activated $A L K$ fusion gene promotes cancer development by initiating some oncogenic pathways including MAPK, PI3K-Akt, JAKSTAT, and PLCY [197]. ALK-TKI has dramatically prolonged the survival of $A L K$-arranged patients [198]. Similar to EGFR-mutation, $A L K$ rearrangement is also related to the poor response to $\alpha-\mathrm{PD}-1 / \mathrm{PD}-\mathrm{L} 1$ [199]. A retrospective analysis showed that the co-expression of PD-L1 and CD8 was rare in $A L K$-arranged tumors, which might contribute to the lower response rate to $\alpha$-PD-1/PD-L1 [200]. Overexpressed ALK fusion protein increased PD-L1 level, promoting the apoptosis of tumor-infiltrating T cells [201]. Besides, ALK inhibition induced immunogenic cell death in $A L K$-arranged cancer cells and conferred the protection of tumor rechallenge in the mouse model [202]. Combination therapy of $\alpha-P D-1$ and ceritinib had an enhanced antitumor efficacy in NPM1-ALK ${ }^{+}$R80 model [202].

It should be noted that ALK-TKI combined with $\alpha$-PD-1/PD-L1 might increase treatment-associated hepatotoxicity. In the phase $1 / 2$ study CheckMate-370, $38 \%$ of patients receiving nivolumab plus crizotinib developed severe hepatic toxicities, leading to the termination of the enrollment [203]. Moreover, pembrolizumab plus crizotinib also showed intolerable hepatotoxicity in NSCLC [204]. Conversely, some other combination strategies such as atezolizumab plus alectinib and avelumab plus lorlatinib had a manageable safety profile, indicating the hepatotoxicity might be ALK-TKI specific $[205,206]$. Additionally, the timing and sequence of combination therapy also influence treatment toxicity, which should be further validated in clinical studies [186, 207].

\footnotetext{
(See figure on next page.)

Fig. 2 The synergistic antitumor efficacies and mechanisms of a-PD-1/PD-L1 in combination with other novel therapies. a The co-inhibitory and co-stimulatory pathways regulating the activities of T cells or NK cells. The green circle refers to co-stimulatory pathway, and the red circle refers to co-inhibitory pathway. b Targeted therapy synergizes with a-PD-1/PD-L1. Oncogenic pathways such as MAPK and PI3K-AKT promote PD-L1 transcription. Targeted therapies including EGFR-TKI, ALK-TKI, and RAS inhibitor not only directly retard tumor growth, but also decrease intrinsic PD-L1 expression. Moreover, STING agonist enhances DC function by activating STING-IFN-I pathway. cThe bifunctional and bispecific antibody containing a-PD-L1 moiety. The structures of M7824 and YM101. d The effect of gut microbiota on antitumor immunity. Gut microbiota regulates DC function, Th1-skweing immunity, Th17 polarization, Treg differentiation, and cytokines secretion. Altered gut mucosa immunity could influence the effect of systemic anticancer immunotherapy. Abbreviations: EGFR-TKI, epidermal growth factor receptor-tyrosine kinase inhibitor; ALK, anaplastic lymphoma kinase; PARP, Poly (ADP-ribose) polymerase; DSB, double-strand break; STING, stimulator of interferon genes
} 
a PD-L1 CD80/86 Gal-9/Ceacam1/ PVRL2 CD112/ MHC-II/Gal-3/

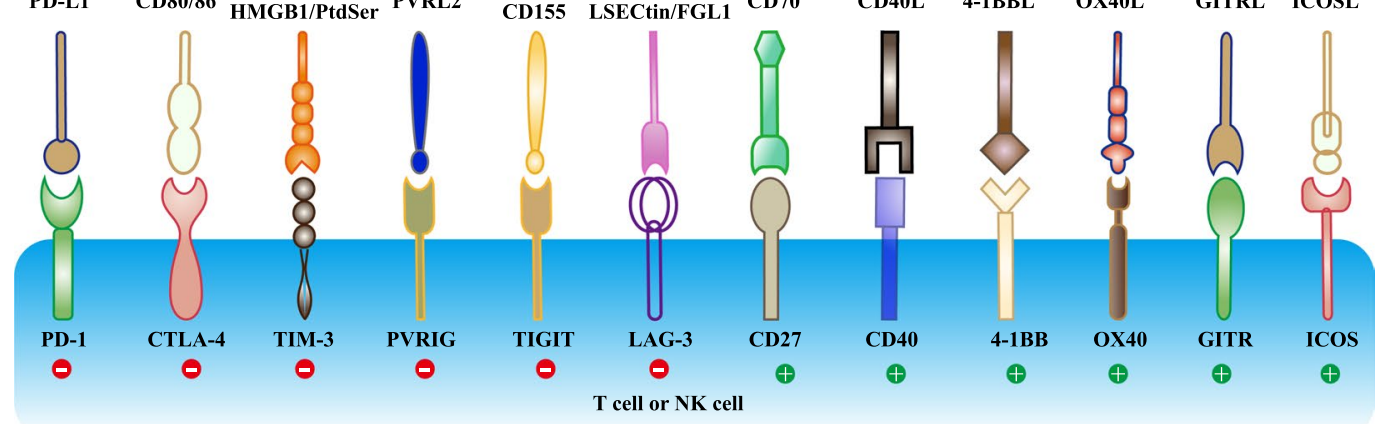

b

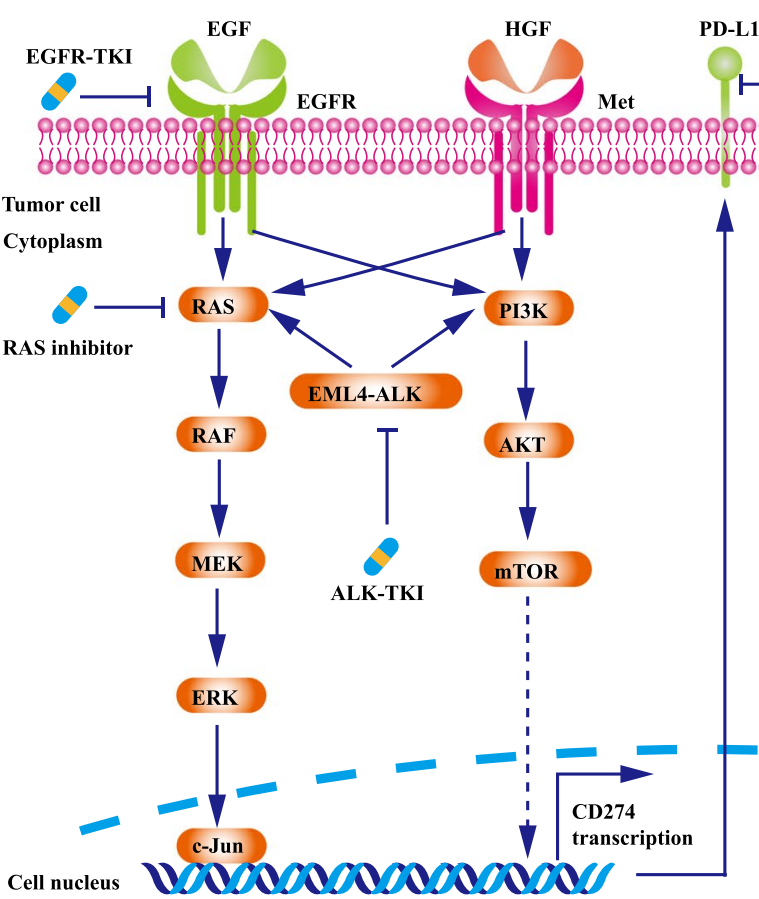

PD-L1

IFN-I

$\Lambda$

pяp९p

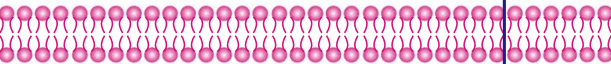

Tumor cell

Cytoplas
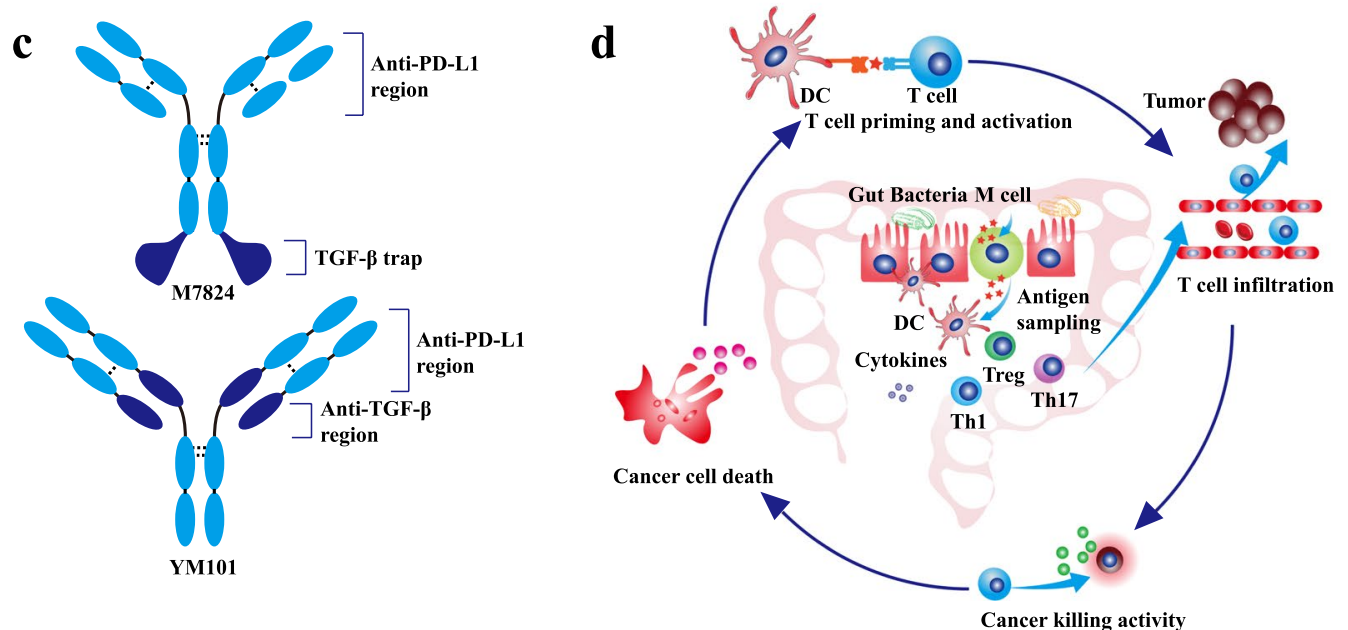

Fig. 2 (See legend on previous page.) 
Table 6 The clinical trials exploring the efficacy of a-PD-1/PD-L1 combined with targeted therapy (except for angiogenesis inhibitor)

\begin{tabular}{|c|c|c|c|c|c|}
\hline Clinical trial & Phase & a-PD-1/PD-L1 & Targeted therapy (Target) & Cancer type & Primary outcome measures \\
\hline NCT01454102 & 1 & Nivolumab & Erlotinib (EGFR) & NSCLC & Safety \\
\hline NCT02013219 & 1 & Atezolizumab & Erlotinib (EGFR) & NSCLC & Safety, RP2D \\
\hline NCT02143466 & 1 & Durvalumab & Osimertinib (EGFR) & NSCLC & Safety \\
\hline NCT02454933 & 3 & Durvalumab & Osimertinib (EGFR) & NSCLC & Safety \\
\hline NCT02574078 & $1 / 2$ & Nivolumab & Crizotinib (Met/ALK/ROS) & NSCLC & Safety \\
\hline NCT02511184 & 1 & Pembrolizumab & Crizotinib (Met/ALK/ROS) & NSCLC & Safety \\
\hline NCT02013219 & 1 & Atezolizumab & Alectinib (ALK FLT3/RET) & NSCLC & Safety, RP2D \\
\hline NCT02584634 & 2 & Avelumab & Crizotinib (Met/ALK/ROS) & NSCLC & ORR, Safety \\
\hline NCT02660034 & 1 & Tislelizumab & Pamiparib (PARP) & Solid tumor & Safety, ORR, PFS, DOR, DCR, CBR, OS \\
\hline NCT04475939 & 3 & Pembrolizumab & Niraparib (PARP) & NSCLC & PFS, OS \\
\hline NCT02657889 & $1 / 2$ & Pembrolizumab & Niraparib (PARP) & TNBC, Ovarian cancer & Safety, ORR \\
\hline NCT02734004 & 2 & Durvalumab & Olaparib (PARP) & Ovarian cancer & DCR, ORR, Safety \\
\hline NCT02484404 & $1 / 2$ & Durvalumab & Olaparib (PARP) & Solid tumor & RP2D, ORR \\
\hline NCT01988896 & 1 & Atezolizumab & Cobimetinib (MEK) & Solid tumor & Safety, RP2D \\
\hline NCT02322814 & 2 & Atezolizumab & Cobimetinib (MEK) & TNBC & PFS, ORR \\
\hline NCT02788279 & 3 & Atezolizumab & Cobimetinib (MEK) & Colorectal cancer & OS \\
\hline NCT03600883 & $1 / 2$ & Unspecified & AMG 510 (KRAS) & KRAS p.G12C mutant solid tumor & Safety \\
\hline NCT02972034 & 1 & Pembrolizumab & MK-8353 (ERK) & Solid tumor & Safety \\
\hline NCT02967692 & 3 & PDR001 & $\begin{array}{l}\text { Dabrafenib (RAF) and Trametinib } \\
\text { (MEK) }\end{array}$ & Melanoma & Safety, PFS \\
\hline NCT04017650 & $1 / 2$ & Nivolumab & $\begin{array}{l}\text { Encorafenib (RAF) and Cetuximab } \\
\text { (EGFR) }\end{array}$ & Colorectal cancer & Best radiographic response; Safety \\
\hline NCT03502733 & 1 & Nivolumab & Copanlisib (PI3K) & Solid tumor and lymphoma & Safety \\
\hline NCT03395899 & 2 & Atezolizumab & Ipatasertib (AKT) & Breast cancer & 2-fold increase in $\mathrm{GzmB}^{+} \mathrm{CD}^{+} \mathrm{T}$ cell \\
\hline NCT02393248 & $1 / 2$ & Pembrolizumab & Pemigatinib (FGFR) & Solid tumor & $\begin{array}{l}\text { Maximum tolerated dose, Pharma- } \\
\text { codynamics }\end{array}$ \\
\hline NCT03123055 & $1 / 2$ & Pembrolizumab & B-701 (FGFR) & Urothelial cell carcinoma & Safety, ORR \\
\hline NCT02819596 & 2 & Durvalumab & Savolitinib (c-MET) & Renal cell carcinoma & Safety, ORR \\
\hline NCT02779751 & 1 & Pembrolizumab & Abemaciclib (CDK4/6) & NSCLC, Breast cancer & Safety \\
\hline NCT04000529 & 1 & Spartalizumab & TNO155 (SHP-2) & Solid tumor & Safety \\
\hline
\end{tabular}

Abbreviations: NSCLC non-small cell lung cancer, PFS progression-free survival, OS overall survival, $R P 2 D$ recommended phase 2 dose, DOR duration of response, DCR disease control rate, CBR clinical benefit rate

\section{RAS-targeted therapy plus a-PD-1/PD-L1}

RAS family (KRAS, NRAS and HRAS) is frequently mutated in cancer cells. Mutated KRAS is a well-established driver gene of NSCLC, colorectal cancer, and pancreatic cancer [208]. In normal cells, RAS is activated by growth factor receptors such as EGFR. RAS is a small G protein, toggling between GTP-bound state (active) and GDP-bound state (inactive). In active state, RAS triggers several downstream pathways including MAPK and PI3K-AKT [209]. In tumor cells, mutations in RAS disturb this switch between GTP-bound state and GDPbound state. As a result, RAS is locked in GTP-bound state, leading to the hyperactive downstream pathways and tumor growth $[209,210]$. Recent studies have shown that RAS and its downstream pathways participated in cancer immune escape: negatively regulating MHC-I expression on cancer cells, increasing the cell-intrinsic
PD-L1 level, elevating immune suppression-associated cytokine production [211, 212]. RAS-targeted therapy abrogated RAS-MAPK/PI3K-AKT-involved immune evasion, synergizing with $\alpha$-PD-1/PD-L1 [213, 214].

In the phase 1 study NCT01988896, atezolizumab plus cobimetinib (MEK inhibitor) had a manageable safety profile and clinical activity in advanced solid tumors, regardless of KRAS/BRAF status [215]. However, in the phase 2 study NCT02322814, atezolizumab plus cobimetinib and taxane had no improvement in ORR in TNBC, relative to cobimetinib plus taxane [216]. Moreover, in the phase 3 study NCT02788279 exploring the efficacy of atezolizumab plus cobimetinib in metastatic colorectal cancer, the primary endpoint of improved OS (atezolizumab plus cobimetinib vs. regorafenib) could not be reached [217]. At present, other combination strategies including $\alpha$-PD-1/PD-L1 plus AMG 510 
(RAS inhibitor) (NCT03600883), MK-8353 (ERK inhibitor) plus pembrolizumab (NCT02972034), PDR001 $(\alpha-\mathrm{PD}-1)$ plus dabrafenib (RAF inhibitor) and trametinib (MEK inhibitor) (NCT02967692), nivolumab plus encorafenib (RAF inhibitor) and cetuximab ( $\alpha$-EGFR) (NCT04017650), nivolumab plus copanlisib (PI3K inhibitor) with or without ipilimumab (NCT03502733), atezolizumab plus ipatasertib (AKT inhibitor) (NCT03395899) are still in clinical trials [218].

\section{Poly (ADP-ribose) polymerase (PARP) inhibitor plus a-PD-1/ PD-L1}

Normal cells preferentially repair double strand break (DSB) via homologous recombination (HR). However, some HR-deficient (e.g. BRCA1/2 mutant) cancer cells only repair DSB by nonhomologous end joining, which is a low fidelity repair pathway [219]. As a result, chromosomal rearrangements are accumulated in cancer cells, eventually leading to cell death [220]. Therefore, intact single-strand break (SSB) repair pathway is essential to these HR-deficient cancer cells. Based on this synthetic lethality theory, interfering SSB could destroy HR-deficient cancer cells [221]. As the core of SSB repair, PARP is the ideal target for drug development [222]. Besides synthetic lethal effect, PARP inhibitor (PARPi) modulates the TME and promotes the antitumor immune response [223]. Firstly, PARPi activates cGAS-STING pathway in cancer cells and increases $T$ cell recruitment [224]. Moreover, PARPi upregulates PD-L1 expression by inactivating GSK3 $\beta$ signaling, which attenuates antitumor immunity [225]. Inspired by the results of preclinical studies, numerous clinical studies are ongoing to evaluate the efficacy of PARPi combined with $\alpha$-PD-1/PD-L1 [219].

In the phase 1 study NCT02660034, pamiparib plus tislelizumab was well-tolerated, and $20 \%$ of patients with advanced solid tumors achieved an objective response at a median follow-up of 8.3 months [226]. Additionally, in the phase 2 study JASPER, niraparib plus pembrolizumab exhibited a powerful antitumor activity especially in PD$\mathrm{L} 1{ }^{\text {high }}$ (tumor proportion scores $\mathrm{TPS} \geq 50 \%$ ) advanced NSCLC patients (ORR: 56.3\%) [227]. Moreover, in the phase $1 / 2$ study KEYNOTE-162, niraparib plus pembrolizumab was tolerable, with a considerable antitumor efficacy in recurrent ovarian carcinoma (ORR: 18\%; DCR: 65\%) [228]. Besides, olaparib and durvalumab arm also had a higher ORR than that reported for PARPi treatment in germline BRCA-mutated platinum-sensitive relapsed ovarian cancer [229]. Accumulating evidence indicates that PARPi plus $\alpha-\mathrm{PD}-1 / \mathrm{PD}-\mathrm{L} 1$ is a promising combination strategy in multiple types of cancers, including metastatic castrate-resistant prostate cancer and metastatic TNBC [230, 231].

\section{a-PD-1/PD-L1 plus other novel targeted therapies}

Dysregulated fibroblast growth factor-fibroblast growth factor receptor (FGF-FGFR) signaling participates in cancer development by activating MAPK, PI3K, and PLC- $\gamma$ pathways [232, 233]. Mutant FGFR signaling might be related to the poor response to $\alpha-\mathrm{PD}-1 / \mathrm{PD}-\mathrm{L} 1$, and FGFR inhibitor synergized with $\alpha-\mathrm{PD}-1 / \mathrm{PD}-\mathrm{L} 1$ in $\mathrm{FGFR}^{\text {mut }}$ models [234]. The combination of erdafitinib (FGFR inhibitor) and $\alpha-\mathrm{PD}-1$ broadened the TCR repertoire and increased $\mathrm{T}$ cell fraction, contributing to the superior antitumor efficacy [234]. Besides, lenvatinib (VEGFR/ FGFR inhibitor) plus $\alpha$-PD-1 also showed a synergistic antitumor effect in the murine HCC model [235]. The clinical studies exploring the efficacy of FGFR inhibitor plus $\alpha-P D-1$ are still undergoing. The interim results of phase 1/2 study NCT02393248 indicated pemigatinib (FGFR inhibitor) combined with pembrolizumab therapy was tolerable, with a potent antitumor effect in FGFR ${ }^{\text {mut }}$ patients [236]. Besides, the preliminary results of phase $1 / 2$ study NCT03123055 demonstrated that vofatamab (FGFR inhibitor) plus pembrolizumab had an encouraging effect in FGFR ${ }^{\mathrm{WT}}$ metastatic urothelial carcinoma [237].

c-MET is also known as hepatocyte growth factor receptor (HGFR). Activated c-MET signaling triggers downstream MAPK, PI3K-AKT, RAC1, and FAK pathways [238]. c-MET signaling is hyperactivated in multiple cancers, due to $M E T$ mutations, amplification, or rearrangement [238]. c-MET signaling upregulated PD-L1 expression, and c-MET inhibitor impaired intrinsic and IFN- $\gamma$-induced PD-L1 expression [239-241]. In the phase 2 study NCT02819596, savolitinib (c-MET inhibitor) plus durvalumab had clinical activity in MET-driven papillary renal cancer (Confirmed RR: $57 \%$, median PFS: 10.5 months, median OS: 27.4 months) [242].

Cyclin-dependent kinase 4/6 (CDK4/6) is an essential component of cell cycle, which cooperates with cyclin D to promote cell cycle G1/S transition [243]. CDK4/6 inhibitors suppress tumor growth by cell cycle arrest [243]. Besides interfering cell division, CDK4/6 inhibitors also had immunomodulatory activity. CDK4/6 inhibitors promoted NF- $\mathrm{KB}$ activation, increased $\mathrm{T}$ cell chemoattractant and PD-L1 level, and prevented PD-L1 degradation in cancer cells [244]. Besides, CDK4/6 inhibitors upregulated NFAT activity and elevated effector gene expression in T cells [244]. CDK4/6 inhibitors improved the efficacy of $\alpha-P D-1$ in murine models by enhancing lymphocyte infiltration and TIL activities [245-248]. The interim data of phase 1b study NCT02779751 showed that abemaciclib (CDK4/6 inhibitor) plus pembrolizumab had antitumor activity in $K R A S^{\text {mut }}$ non-squamous NSCLC [249]. 
SHP2 is an oncogenic protein belonging to protein tyrosine phosphatases family [250]. As the convergent node of MAPK, PI3K-AKT, JAK-STAT, and PD-1 pathways, SHP2 widely regulates multiple cancer-associated processes such as cell survival and immune escape [251]. SHP2 inhibition increased PD-L1 and MHC-I expression by augmenting intrinsic IFN- $\gamma$ in cancer cells [252]. SHP2 inhibitor enhanced the efficacy of $\alpha-P D-1$ in murine tumor models [252-254]. A clinical study exploring SHP2 inhibitor combined with $\alpha-\mathrm{PD}-1$ is still ongoing (NCT04000529), and the final data of this combination study are not yet available [255].

\section{STING agonist plus $\mathrm{a}-\mathrm{PD}-1 / \mathrm{PD}-\mathrm{L} 1$}

\section{STING pathway and STING agonist}

Cytosolic chromatin fragments and micronuclei are commonly accumulated during malignant transformation, increasing the probability of cytosolic DNA leakage in cancer cells or tumor-derived DNA uptake in DCs [256]. cGAS-STING pathway is a cytosolic DNA sensing signaling. Cytosolic dsDNA binds to cGAS, catalyzing the generation of cyclic GMP-AMP (cGAMP). Stimulated by cGAMP, STING changes from monomer to dimer and translocates from ER to perinuclear microsome. Then, STING recruits and phosphorylates TBK1, which further activates downstream IRF3 and upregulates IFN-I [257259]. Besides, STING also increases IFN-I by activating NF- $\mathrm{kB}$ pathway [260]. IFN-I is a versatile immune stimulator that could enhance the functions of DC, NK, and T cells [261]. Given the critical role of cGAS-STING pathway in bridging innate and adaptive immunity, STING is the potential target for cancer immunotherapy.

Dimethyloxoxanthenyl acetic acid (DMXAA) is the first STING agonist which failed in the clinical trials [262]. Further investigation has identified that DMXAA is a mouse-specific STING agonist, with a subtle influence on human STING pathway [263, 264]. Sharing similar structures and biological characteristics with cGAMP, some natural and artificially synthetic cyclic dinucleotides (CDNs) are developed as STING agonists for cancer immunotherapy [265-267]. Generally, CDNs have two main flaws: poor transmembrane capability and depending on intratumor injection. Recently, some novel STING agonists such as diABZI and MSA-2 have been developed which could be systemically administrated [268, 269]. Besides, manganese is also identified as a natural STING agonist, playing an important role in antitumor immunity [270, 271].

\section{STING agonist plus a-PD-1/PD-L1}

The combination therapy of STING agonist and $\alpha-P D-1 /$ PD-L1 simultaneously boosts innate immunity and adaptive immunity, effectively overcoming resistance to immunotherapy. On the one hand, STING agonist promotes immune cell infiltration and enhances the function of APC, NK, and T cells [272-274]. On the other hand, $\alpha$-PD-1/PD-L1 antibodies take advantage of STING agonist-induced PD-L1 upregulation [273]. Up to now, multiple clinical trials of STING agonist combined with $\alpha-\mathrm{PD}-1 / \mathrm{PD}-\mathrm{L} 1$ are ongoing. The preliminary data showed that some combination therapies (e.g. ADU-S100 plus spartalizumab, MK-1454 plus pembrolizumab, manganese plus $\alpha-P D-1)$ had encouraging antitumor activity with a tolerable safety profile $[270,275,276]$.

\section{Bispecific/bifunctional antibody targeting PD-1/ PD-L1}

Dual targeting by bispecific/bifunctional antibodies has emerged as an option for combination therapy. Bispecific/bifunctional antibody simultaneously blocks two molecules with one drug, having a strategic advantage over the combination therapy (Table 7) [277].

\section{TGF- $\beta \times$ PD-L1 bispecific/bifunctional antibody}

TGF- $\beta$ is a well-studied immunoinhibitory cytokine: restraining immune cell infiltration, inducing Treg differentiation, and hampering the functions of T cell, APC, and NK [17]. Hyperactivated TGF- $\beta$ signaling was associated with the poor response to $\alpha-\mathrm{PD}-1 / \mathrm{PD}-\mathrm{L} 1$, and blocking TGF- $\beta$ significantly improved the efficacy of $\alpha-$ PD-1/PD-L1 [299-302]. M7824 is a TGF- $\beta \times$ PD-L1 bifunctional protein, which had potent antitumor activity in murine tumor models (Fig. 2c) [278]. The results of phase 1 studies were encouraging, and patients receiving M7824 had a higher ORR, compared to previous data [303, 304]. Besides, in the phase 1 study NCT03710265, SHR-1701 (TGF- $\beta \times$ PD-L1 bifunctional antibody) showed encouraging antitumor activity [280]. Apart from bifunctional antibody, the TGF $-\beta \times$ PD-L1 bispecific antibody YM101 also exhibited robust antitumor activity in immune-excluded tumor models [279]. Further investigation showed that YM101 promoted T cell infiltration, enhanced $T$ cell function, impaired cancer-associated fibroblasts (CAF) activity, and induced macrophage polarization toward M2-like phenotype [279]. The antitumor mechanisms of TGF- $\beta \times$ PD-L1 bispecific/bifunctional antibody are well-understood, thus an enormous number of resources are spent on the development of analogical antibodies.

\section{Bispecific antibody targeting two inhibitory immune checkpoints}

The resistance to $\alpha-\mathrm{PD}-1 / \mathrm{PD}-\mathrm{L} 1$ is related to the upregulation of other immune checkpoints. Therefore, bispecific antibodies targeting two inhibitory immune checkpoints 
Table 7 Bispecific/bifunctional antibodies targeting PD-1/PD-L1

\begin{tabular}{|c|c|c|c|}
\hline Target & Antibody Product & Company/Authors & Reference \\
\hline \multirow{3}{*}{ TGF- $\beta \times$ PD-L1 } & M7824 & Merck KGaA & [278] \\
\hline & YM101 & Wuhan YZY Biopharma & [279] \\
\hline & SHR-1701 & Hengrui Pharmaceuticals & [280] \\
\hline CTLA-4 × PD-L1 & KN046 & Alphamab Oncology & [281] \\
\hline \multirow[t]{2}{*}{ CTLA-4 × PD-1 } & MGD019 & MacroGenics & [282] \\
\hline & MEDI5752 & AstraZeneca & [283] \\
\hline LAG-3 × PD-L1 & |B|323 & Innovent Biologics & [284] \\
\hline LAG-3 × PD-1 & Tebotelimab & MacroGenics & [285] \\
\hline TIM-3 × PD-L1 & LY3415244 & Eli Lilly & [286] \\
\hline TIGIT×PD-L1 & Not given & Novamab Biopharmaceuticals & [287] \\
\hline \multirow{3}{*}{ 4-1BB × PD-L1 } & MCLA-145 & Merus and Incyte & [288] \\
\hline & ABL503 & ABL Bio & [289] \\
\hline & PM1003 & Biotheus & [290] \\
\hline CD27 × PD-L1 & CDX-527 & Celldex Therapeutics & [291] \\
\hline \multirow[t]{4}{*}{ c-Met×PD-1 } & Not given & Yuan et. al & [292] \\
\hline & Not given & Hou et. al & [293] \\
\hline & Not given & Wu et. al & [294] \\
\hline & Not given & Sun et. al & [295] \\
\hline EGFR $\times$ PD-L1 & Not given & Koopmans et. al & [296] \\
\hline PD-1 × PD-L1 & LY3434172 & Eli Lilly & [297] \\
\hline CD47 × PD-L1 & IBI322 & Innovent Biologics & [298] \\
\hline
\end{tabular}

might relieve $\alpha$-PD-1/PD-L1 resistance. Numerous bispecific antibodies have been developed, including CTLA-4 $\times$ PD-L1 (KN046) [281], CTLA-4 $\times$ PD-1 (MGD019 and MEDI5752) [282, 283], LAG-3 $\times$ PD-L1 (IBI323) [284], LAG-3 × PD-1 (Tebotelimab) [285], TIM-3 $\times$ PD-L1 (LY3415244) [286], TIM-3 $\times$ PD-1 [305], TIGIT $\times$ PD-L1 [287]. Most bispecific antibodies achieved excellent antitumor efficacies in murine tumor models. Some bispecific antibodies have been in clinical trials, showing preliminary antitumor activity.

\section{Bispecific antibody targeting PD-1/PD-L1 and co-stimulatory molecules}

As mentioned above, agonists targeting co-stimulatory molecules synergize $\alpha-\mathrm{PD}-1 / \mathrm{PD}-\mathrm{L} 1$. It is rational to develop bispecific antibodies targeting PD-1/ PD-L1 and co-stimulatory molecules to optimally engage antitumor immune response. Multiple bispecific antibodies have been successfully constructed, including 4-1BB $\times$ PD-L1 (MCLA-145, ABL503, PM1003) [288-290] and CD27 $\times$ PD-L1 (CDX-527) [291]. These bispecific antibodies augmented the functions of TILs and exerted a powerful antitumor efficacy [288-291].

\section{Other bispecific antibodies targeting PD-1/PD-L1}

The synergistic effect between $\mathrm{C}-\mathrm{MET}$ inhibitor and $\alpha-P D-1 / P D-L 1$ has been verified [306]. c-MET $\times$ PD-1 bispecific antibodies simultaneously reversed c-Metmediated cell proliferation and migration and enhanced $\mathrm{T}$ cell functions [292-295]. Moreover, avoiding 'ontarget/off-tumor' binding to PD-L1 on nonmalignant cells, EGFR $\times$ PD-L1 bispecific antibody was developed for EGFR+ tumors [296]. This antibody had an enhanced tumor specificity, reducing the risks of the indiscriminate reactivation of antitumor $\mathrm{T}$ cells and severe treatment-related adverse events [296]. These tumor-associated antigen $\times \mathrm{PD}-1 / \mathrm{PD}$-L1 bispecific antibodies might have a great advantage in efficacy and safety. Besides, PD-1 $\times$ PD-L1 (LY3434172) and CD47 $\times$ PD-L1 (IBI322) bispecific antibodies had enhanced immunomodulatory properties and improved antitumor activity, relative to monospecific PD-1 and PD-L1 antibodies [297, 298].

\section{Other novel combination strategies FMT plus a-PD-1/PD-L1}

The influence of gut microbiota on host immunity is multifaceted, simultaneously regulating the gut mucosal immune system and systemic immune system (Fig. 2d) [307-310]. It was reported that the gut microbiota of immunotherapy-sensitive patients was distinct from 
that of immunotherapy-resistant populations [311, 312]. Some specific bacteria including Bifidobacterium, Faecalibacterium, Akkermansia muciniphila, and Bacteroides fragilis enhanced the functions of $\mathrm{DC}$ and $\mathrm{T}$ cells, contributing to the better response to immunotherapy [313]. Conversely, bacteria including Bacteroidales, Ruminococcus obeum, and Roseburia intestinalis increased the immunoinhibitory components such as MDSC and Treg, impairing the efficacy of immunotherapy [313]. Besides, manipulating gut microbiota composition could improve the response to $\alpha-\mathrm{PD}-1 / \mathrm{PD}-\mathrm{L} 1$ [311, 314-316]. The results of two phase 1 clinical studies NCT03341143 and NCT03353402 showed responder-derived FMT effectively relieved the resistance to $\alpha-\mathrm{PD}-1 / \mathrm{PD}-\mathrm{L} 1$ in some melanoma patients, having implications for modulating gut microbiota in cancer immunotherapy [26, 317].

\section{Immunostimulatory cytokine treatment}

or immunoinhibitory cytokine blockade plus a-PD-1/PD-L1 Some cytokines including GM-CSF, IFN- $\alpha$, IL-2, IL-7, IL-12, IL-15, IL-18, and IL-21 have antitumor activity via stimulating immunity, inhibiting proliferation, or inducing apoptosis in cancer cells [318]. Moreover, neutralizing cytokines including TGF- $\beta$ and IL- 6 potentiates antitumor immunity $[319,320]$. The safety and efficacy of $\alpha$-PD-1/PD-L1 combined with IL-2 pathway agonist (NKTR-214/BEMPEG) [321], PEGylated IL-10 (Pegilodecakin) [322], IL-12 plasmid (Tavo) [323], IL-15 agonist (ALT-803) [324], or PEGylated IFN- $\alpha$ [325] had been validated in cancer patients. The preliminary results support further clinical trials to assess the optimal sequencing and combination of $\alpha-\mathrm{PD}-1 / \mathrm{PD}-\mathrm{L} 1$ and cytokine therapy.

\section{Epigenetic modifiers plus a-PD-1/PD-L1}

Epigenetic alterations such as histone acetylation regulate PD-L1 expression [188]. Beyond direct cytotoxicity, histone deacetylases (HDAC) inhibitors changed immunogenicity and enhanced antitumor immunity, via decreasing MDSC ratio and upregulating MHC-I/II, CD40, CD80, and CD86 expression [326-328]. HDAC inhibitor combined with $\alpha$-PD-1/PD-L1 has shown a synergistic antitumor effect in murine tumor models [329331]. Inspired by the encouraging results of preclinical studies, the combination therapy of entinostat (HDAC1/3 inhibitor) and pembrolizumab is in clinical trials. The preliminary results (NCT02697630) showed that entinostat plus pembrolizumab induced durable responses in some patients with metastatic uveal melanoma, and more entinostat-involved combination regimes such as entinostat plus avelumab (NCT02915523), nivolumab (NCT03838042), or M7824 (NCT04708470) are still in clinical evaluation [332].

\section{Metabolic modulators plus a-PD-1/PD-L1}

The engagement of adenosine $2 \mathrm{~A}$ receptor (A2AR) with adenosine elicits immunoinhibitory effects: suppressing the activities of tumor-infiltrating CD8+ T cells and hampering the function and differentiation of DCs [333, 334]. The accumulated adenosine in the TME promotes cancer immune evasion, and A2AR blockade rescues immune cell function $[335,336]$. The results of a phase 1 study showed that ciforadenant (A2AR inhibitor) combined with atezolizumab effectively prolonged PFS and OS in RCC patients [337]. Besides, other metabolic modulators such as glutaminase inhibitor also had a synergistic effect with $\alpha$-PD-1/PD-L1 in murine tumor models [338].

\section{Chimeric antigen receptor-T (CAR-T) cell therapy plus a-PD-1/PD-L1}

CAR-T cells are genetically engineered $T$ cells, which could recognize and bind cancer antigen in an MHCindependent manner [339]. CAR-T cell therapy provides numerous cancer-reactive $\mathrm{T}$ cells and overcomes MHC downregulation-mediated cancer immune evasion [339]. However, the efficacy of CAR-T cell therapy is modest in most solid tumors, which is partly attributed to the immunosuppressive TME [340]. $\alpha$-PD-1/PD-L1 enhanced CAR-T cell therapy by rescuing CAR-T cell exhaustion [341-343]. The results of phase 1 study demonstrated CAR-T cell therapy combined with $\alpha-\mathrm{PD}-1 /$ PD-L1 had confirmed antitumor activity in patients with malignant pleural diseases [344]. Moreover, modified CAR-T cells, which secret PD-1-blocking single-chain variable fragments (scFv), had improved antitumor activity by an autocrine and paracrine manner [345]. This combination strategy protects CAR-T cells from immune exhaustion and optimizes CAR-T cell efficacy.

\section{Perspective and conclusion}

Although dozens of combination regimens exhibit potent antitumor activities in preclinical studies, some positive preclinical findings could not be validated in the clinic. At present, only combinations of $\alpha-\mathrm{PD}-1 / \mathrm{PD}-\mathrm{L} 1$ with chemotherapy, angiogenesis inhibitor, or $\alpha$-CTLA-4 are approved by the FDA or NMPA. For most combinations, the striking antitumor activities are limited in animal tumor models. Therefore, how to select an optimal preclinical model is a grand challenge to identify the activities of combination regimens. Relative to widely used syngeneic murine models, humanized patient-derived models could provide a more precious efficacy evaluation. Besides, combination therapy increases the risk of irAEs and the cost of health care. Inappropriate combination treatments will expose patients to significantly higher toxicities. How to optimize administration regimen, 
including dosage, timing, and sequence, is another challenge for the development of combination therapy. Lastly, it is still unclear how to select appropriate combination therapy and find biomarkers predicting treatment response. Considering the heterogeneity and evolution of tumors, liquid biopsy could dynamically monitor the immune landscape of the TME and provide a real-time biomarker for guiding precision immunotherapy [346]. We believe individualized combination therapy should be provided based on patient's immune profiling and other predictive biomarkers. A comprehensive framework integrating genome, transcriptome, immune profiling, microbiome could be adopted to select patients benefiting from combinations.

For patients with non-inflamed tumors, $\alpha$-PD-1/ PD-L1 monotherapy scarcely provides clinical benefits, and a personalized combination is needed to overcome drug resistance. In the background of immune-excluded,

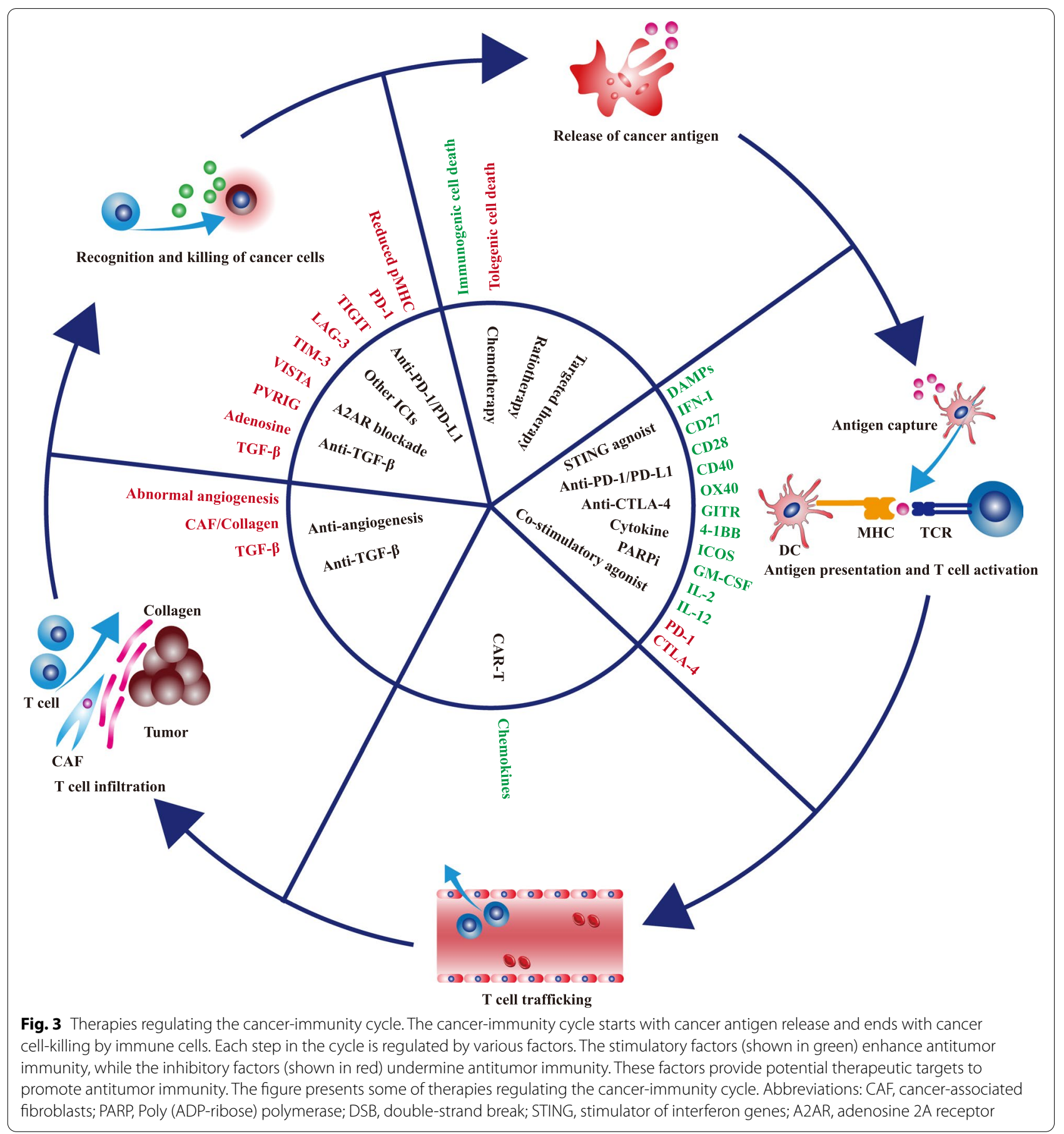


therapies such as TGF- $\beta$ blocker could rescue the restrained $\mathrm{T}$ cell penetration by inhibiting CAF activities and reducing peritumoral collagen deposition. In the context of immune-desert, therapies such as radiotherapy, chemotherapy, and STING agonist could overcome low immunogenicity-mediated immune tolerance by inducing immunogenic cell death, increasing cancer antigen release, and promoting the function of APC. Combining these therapies with $\alpha$-PD-1/PD-L1 simultaneously boosts multiple processes in the cancerimmunity cycle, reshapes the TME, and substantially promotes the transformation from non-inflamed to inflamed tumors (Fig. 3). Besides, with the development of next-generation $\alpha-\mathrm{PD}-1 / \mathrm{PD}-\mathrm{L} 1 \mathrm{drugs}$ such as bifunctional or bispecific antibodies, the indication of $\alpha$-PD-1/ PD-L1 therapies would be greatly extended, and more patients could benefit from the updated $\alpha-\mathrm{PD}-1 / \mathrm{PD}-\mathrm{L} 1$ treatments.

\begin{abstract}
Abbreviations
PD-1: Programmed cell death 1; TCR:T cell receptor; SHP-2: Src homology region 2 domain-containing phosphatase; PAPC: Professional antigen presentation cell; STING: Stimulator of interferon genes; FMT: Fecal microbiota transplant; TME: Tumor microenvironment; DAMP: Damage-associated molecular pattern; CRT: Calreticulin; HMGB1: High-mobility group box 1; DC: Dendritic cell; Treg: Regulatory T cell; TAM: Tumor-associated macrophage; MDSC: Myeloid-derived suppressor cell; TIL: Tumor-infiltrating lymphocyte; PFS: Progression-free survival; OS: Overall survival; ORR: Objective response rate; NSCLC: Non-small cell lung cancer; GEJC: Gastroesophageal junction cancer; TNBC: Triple-negative breast cancer; FDA: Food and drug administration; NMPA: National medical products administration; SBRT: Stereotactic body radiotherapy; VEGF: Endothelial growth factor; ANGPT2: Angiopoietin 2; PLGF: Placental growth factor; EGFR-TKI: Epidermal growth factor receptortyrosine kinase inhibitor; irAE: Immune-related adverse event; ALK: Anaplastic lymphoma kinase; PARP: Poly (ADP-ribose) polymerase; DSB: Double strand break; HR: Homologous recombination; SSB: Single strand break; FGFR: Fibroblast growth factor receptor; HCC: Hepatocellular carcinoma; HGFR: Hepatocyte growth factor receptor; CDK4/6: Cyclin-dependent kinase 4/6; CGAMP: Cyclic GMP-AMP; DMXAA: Dimethyloxoxanthenyl acetic acid; CDN: Cyclic dinucleotide; CAF: Cancer-associated fibroblast; HDAC: Histone deacetylase; A2AR: Adenosine 2A receptor; CAR-T: Chimeric antigen receptor T.
\end{abstract}

\section{Acknowledgements}

Not applicable.

\section{Authors' contributions}

MY drafted the manuscript and prepared the figures. XZ, MN, SZ collected the related references and participated in discussion. $\mathrm{HG}$ and $\mathrm{KW}$ designed this review and revised the manuscript. All authors contributed to this manuscript. All authors read and approved the final manuscript.

\section{Funding}

This work was supported by the National Natural Science Foundation of China (No. 81874120, 82073370).

Availability of data and materials

Not applicable.

\section{Declarations}

Ethics approval and consent to participate

Not applicable.
Consent for publication

Not applicable.

\section{Competing interests}

The authors declare that they have no competing interests.

Received: 11 November 2021 Accepted: 26 December 2021

Published online: 21 January 2022

References

1. Chen DS, Mellman I. Elements of cancer immunity and the cancerimmune set point. Nature. 2017;541:321-30.

2. Marasco M, Berteotti A, Weyershaeuser J, Thorausch N, Sikorska J, Krausze J, et al. Molecular mechanism of SHP2 activation by PD-1 stimulation. Sci Adv. 2020;6:eaay4458.

3. Sheppard KA, Fitz LJ, Lee JM, Benander C, George JA, Wooters J, et al. PD-1 inhibits T-cell receptor induced phosphorylation of the ZAP70/ CD3zeta signalosome and downstream signaling to PKCtheta. FEBS Lett. 2004;574:37-41.

4. Yokosuka T, Takamatsu M, Kobayashi-Imanishi W, Hashimoto-Tane A, Azuma M, Saito T. Programmed cell death 1 forms negative costimulatory microclusters that directly inhibit $\mathrm{T}$ cell receptor signaling by recruiting phosphatase SHP2. J Exp Med. 2012;209:1201-17.

5. Li K, Yuan Z, Lyu J, Ahn E, Davis SJ, Ahmed R, et al. PD-1 suppresses TCR-CD8 cooperativity during T-cell antigen recognition. Nat Commun. 2021;12:2746

6. Bardhan K, Anagnostou T, Boussiotis VA. The PD1:PD-L1/2 pathway from discovery to clinical implementation. Front Immunol. 2016;7:550.

7. Reck M, Rodríguez-Abreu D, Robinson AG, Hui R, Csőszi T, Fülöp A, et al. Pembrolizumab versus chemotherapy for PD-L1-positive non-small-cell lung Cancer. N Engl J Med. 2016;375:1823-33.

8. Motzer RJ, Escudier B, McDermott DF, George S, Hammers HJ, Srinivas S, et al. Nivolumab versus Everolimus in advanced renal-cell carcinoma. N Engl J Med. 2015;373:1803-13.

9. El-Khoueiry AB, Sangro B, Yau T, Crocenzi TS, Kudo M, Hsu C, et al. Nivolumab in patients with advanced hepatocellular carcinoma (CheckMate 040): an open-label, non-comparative, phase 1/2 dose escalation and expansion trial. Lancet. 2017;389:2492-502.

10. Nanda R, Chow LQ, Dees EC, Berger R, Gupta S, Geva R, et al. Pembrolizumab in patients with advanced triple-negative breast Cancer: phase Ib KEYNOTE-012 study. J Clin Oncol. 2016;34:2460-7.

11. Robert C, Schachter J, Long GV, Arance A, Grob JJ, Mortier L, et al. Pembrolizumab versus Ipilimumab in Advanced Melanoma. N Engl J Med. 2015:372:2521-32.

12. Tang B, Yan X, Sheng X, Si L, Cui C, Kong Y, et al. Safety and clinical activity with an anti-PD-1 antibody JS001 in advanced melanoma or urologic cancer patients. J Hematol Oncol. 2019;12:7.

13. Kim JM, Chen DS. Immune escape to PD-L1/PD-1 blockade: seven steps to success (or failure). Ann Oncol. 2016;27:1492-504.

14. Chen DS, Mellman I. Oncology meets immunology: the cancerimmunity cycle. Immunity. 2013;39:1-10.

15. Qin $S, X u L, Y i$ M, Yu S, Wu K, Luo S. Novel immune checkpoint targets: moving beyond PD-1 and CTLA-4. Mol Cancer. 2019;18:155.

16. Yi M, Jiao D, Qin S, Chu Q, Wu K, Li A. Synergistic effect of immune checkpoint blockade and anti-angiogenesis in cancer treatment. Mol Cancer. 2019;18:60.

17. Bai X, Yi M, Jiao Y, Chu Q, Wu K. Blocking TGF- $\beta$ signaling to enhance the efficacy of immune checkpoint inhibitor. Onco Targets Ther. 2019;12:9527-38.

18. Liu T, Han C, Wang S, Fang P, Ma Z, Xu L, et al. Cancer-associated fibroblasts: an emerging target of anti-cancer immunotherapy. J Hematol Oncol. 2019;12:86.

19. Yi M, Xu L, Jiao Y, Luo S, Li A, Wu K. The role of cancer-derived microRNAs in cancer immune escape. J Hematol Oncol. 2020;13:25.

20. Wu Q, Li B, Li J, Sun S, Yuan J, Sun S. Cancer-associated adipocytes as immunomodulators in cancer. Biomark Res. 2021;9:2.

21. Smyth MJ, Ngiow SF, Ribas A, Teng MW. Combination cancer immunotherapies tailored to the tumour microenvironment. Nat Rev Clin Oncol. 2016;13:143-58. 
22. Xu J, Zhang Y, Jia R, Yue C, Chang L, Liu R, et al. Anti-PD-1 antibody SHR1210 combined with Apatinib for advanced hepatocellular carcinoma, gastric, or Esophagogastric junction Cancer: an open-label, dose escalation and expansion study. Clin Cancer Res. 2019;25:515-23.

23. Horn L, Mansfield AS, Szczęsna A, Havel L, Krzakowski M, Hochmair MJ, et al. First-line Atezolizumab plus chemotherapy in extensive-stage small-cell lung Cancer. N Engl J Med. 2018;379:2220-9.

24. Luke JJ, Lemons JM, Karrison TG, Pitroda SP, Melotek JM, Zha Y, et al. Safety and clinical activity of Pembrolizumab and multisite stereotactic body radiotherapy in patients with advanced solid tumors. J Clin Oncol. 2018;36:1611-8.

25. Lee SJ, Yang H, Kim WR, Lee YS, Lee WS, Kong SJ, et al. STING activation normalizes the intraperitoneal vascular-immune microenvironment and suppresses peritoneal carcinomatosis of colon cancer. J Immunother Cancer. 2021;9:e002195.

26. Davar D, Dzutsev AK, McCulloch JA, Rodrigues RR, Chauvin JM, Morrison $\mathrm{RM}$, et al. Fecal microbiota transplant overcomes resistance to anti-PD-1 therapy in melanoma patients. Science. 2021;371:595-602.

27. Ruan $\mathrm{H}, \mathrm{Hu} \mathrm{Q}$, Wen $\mathrm{D}$, Chen $\mathrm{Q}$, Chen $\mathrm{G}$, Lu Y, et al. A dual-bioresponsive drug-delivery depot for combination of epigenetic modulation and immune checkpoint blockade. Adv Mater. 2019;31:e1806957.

28. Ott PA, Hu-Lieskovan S, Chmielowski B, Govindan R, Naing A, Bhardwaj $\mathrm{N}$, et al. A phase Ib trial of personalized Neoantigen therapy plus antiPD-1 in patients with advanced melanoma, non-small cell lung Cancer, or bladder Cancer. Cell. 2020;183:347-62.e24.

29. Yuan X, Yi M, Zhang W, Xu L, Chu Q, Luo S, et al. The biology of combination immunotherapy in recurrent metastatic head and neck cancer. Int J Biochem Cell Biol. 2021;136:106002.

30. Li A, Yi M, Qin S, Song Y, Chu Q, Wu K. Activating cGAS-STING pathway for the optimal effect of cancer immunotherapy. J Hematol Oncol. 2019:12:35.

31. Zhu S, Zhang T, Zheng L, Liu H, Song W, Liu D, et al. Combination strategies to maximize the benefits of cancer immunotherapy. J Hematol Oncol. 2021;14:156.

32. Gotwals P, Cameron S, Cipolletta D, Cremasco V, Crystal A, Hewes $B$, et al. Prospects for combining targeted and conventional cancer therapy with immunotherapy. Nat Rev Cancer. 2017;17:286-301.

33. Obeid M, Tesniere A, Ghiringhelli F, Fimia GM, Apetoh L, Perfettini JL, et al. Calreticulin exposure dictates the immunogenicity of cancer cell death. Nat Med. 2007;13:54-61.

34. Zhu H, Shan Y, Ge K, Lu J, Kong W, Jia C. Oxaliplatin induces immunogenic cell death in hepatocellular carcinoma cells and synergizes with immune checkpoint blockade therapy. Cell Oncol (Dordr). 2020;43:1203-14.

35. Galluzzi L, Humeau J, Buqué A, Zitvogel L, Kroemer G. Immunostimulation with chemotherapy in the era of immune checkpoint inhibitors. Nat Rev Clin Oncol. 2020;17:725-41.

36. Kroemer G, Galluzzi L, Kepp O, Zitvogel L. Immunogenic cell death in cancer therapy. Annu Rev Immunol. 2013;31:51-72.

37. Mathew M, Enzler T, Shu CA, Rizvi NA. Combining chemotherapy with PD-1 blockade in NSCLC. Pharmacol Ther. 2018;186:130-7.

38. Barbon CM, Yang M, Wands GD, Ramesh R, Slusher BS, Hedley ML, et al. Consecutive low doses of cyclophosphamide preferentially target Tregs and potentiate T cell responses induced by DNA PLG microparticle immunization. Cell Immunol. 2010;262:150-61.

39. Tongu M, Harashima N, Monma H, Inao T, Yamada T, Kawauchi $H$, et al. Metronomic chemotherapy with low-dose cyclophosphamide plus gemcitabine can induce anti-tumor T cell immunity in vivo. Cancer Immunol Immunother. 2013;62:383-91.

40. Noordam L, Kaijen MEH, Bezemer K, Cornelissen R, Maat L, Hoogsteden $\mathrm{HC}$, et al. Low-dose cyclophosphamide depletes circulating naïve and activated regulatory T cells in malignant pleural mesothelioma patients synergistically treated with dendritic cell-based immunotherapy. Oncoimmunology. 2018;7:e1474318.

41. Wanderley CW, Colón DF, Luiz JPM, Oliveira FF, Viacava PR, Leite CA, et al. Paclitaxel reduces tumor growth by reprogramming tumorassociated macrophages to an M1 profile in a TLR4-dependent manner. Cancer Res. 2018;78:5891-900.

42. Vincent J, Mignot G, Chalmin F, Ladoire S, Bruchard M, Chevriaux A, et al. 5-fluorouracil selectively kills tumor-associated myeloid-derived suppressor cells resulting in enhanced T cell-dependent antitumor immunity. Cancer Res. 2010;70:3052-61.

43. Alizadeh D, Trad M, Hanke NT, Larmonier CB, Janikashvili N, Bonnotte $B$, et al. Doxorubicin eliminates myeloid-derived suppressor cells and enhances the efficacy of adoptive T-cell transfer in breast cancer. Cancer Res. 2014;74:104-18.

44. Zhang Y, Bush X, Yan B, Chen JA. Gemcitabine nanoparticles promote antitumor immunity against melanoma. Biomaterials. 2019;189:48-59.

45. Kodumudi KN, Woan K, Gilvary DL, Sahakian E, Wei S, Djeu JY. A novel chemoimmunomodulating property of docetaxel: suppression of myeloid-derived suppressor cells in tumor bearers. Clin Cancer Res. 2010;16:4583-94.

46. Wesolowski R, Duggan MC, Stiff A, Markowitz J, Trikha P, Levine KM, et al. Circulating myeloid-derived suppressor cells increase in patients undergoing neo-adjuvant chemotherapy for breast cancer. Cancer Immunol Immunother. 2017;66:1437-47.

47. Schiavoni G, Sistigu A, Valentini M, Mattei F, Sestili P, Spadaro F, et al. Cyclophosphamide synergizes with type I interferons through systemic dendritic cell reactivation and induction of immunogenic tumor apoptosis. Cancer Res. 2011;71:768-78.

48. Zhao T, Ren H, Jia L, Chen J, Xin W, Yan F, et al. Inhibition of HIF-1 a by PX-478 enhances the anti-tumor effect of gemcitabine by inducing immunogenic cell death in pancreatic ductal adenocarcinoma. Oncotarget. 2015;6:2250-62.

49. Tanaka H, Matsushima H, Nishibu A, Clausen BE, Takashima A. Dual therapeutic efficacy of vinblastine as a unique chemotherapeutic agent capable of inducing dendritic cell maturation. Cancer Res. 2009;69:6987-94.

50. Hong X, Dong T, Yi T, Hu J, Zhang Z, Lin S, et al. Impact of 5-Fu/oxaliplatin on mouse dendritic cells and synergetic effect with a colon cancer vaccine. Chin J Cancer Res. 2018:30:197-208.

51. Schaer DA, Geeganage S, Amaladas N, Lu ZH, Rasmussen ER, Sonyi A, et al. The Folate pathway inhibitor Pemetrexed Pleiotropically enhances effects of Cancer immunotherapy. Clin Cancer Res. 2019;25:7175-88.

52. Langer CJ, Gadgeel SM, Borghaei H, Papadimitrakopoulou VA, Patnaik A, Powell SF, et al. Carboplatin and pemetrexed with or without pembrolizumab for advanced, non-squamous non-small-cell lung cancer: a randomised, phase 2 cohort of the open-label KEYNOTE-021 study. Lancet Oncol. 2016;17:1497-508.

53. Gandhi L, Rodríguez-Abreu D, Gadgeel S, Esteban E, Felip E, De Angelis F, et al. Pembrolizumab plus chemotherapy in metastatic non-small-cell lung Cancer. N Engl J Med. 2018:378:2078-92.

54. Paz-Ares L, Luft A, Vicente D, Tafreshi A, Gümüş M, Mazières J, et al. Pembrolizumab plus chemotherapy for squamous non-small-cell lung Cancer. N Engl J Med. 2018;379:2040-51.

55. Cortes J, Cescon DW, Rugo HS, Nowecki Z, Im SA, Yusof MM, et al. Pembrolizumab plus chemotherapy versus placebo plus chemotherapy for previously untreated locally recurrent inoperable or metastatic triplenegative breast cancer (KEYNOTE-355): a randomised, placebo-controlled, double-blind, phase 3 clinical trial. Lancet. 2020;396:1817-28.

56. Sun JM, Shen L, Shah MA, Enzinger P, Adenis A, Doi T, et al. Pembrolizumab plus chemotherapy versus chemotherapy alone for first-line treatment of advanced oesophageal cancer (KEYNOTE-590): a randomised, placebo-controlled, phase 3 study. Lancet. 2021;398:759-71.

57. Janjigian Y, Kawazoe A, Weber P, Luo S, Lonardi S, Kolesnik O, et al. LBA-4 initial data from the phase 3 KEYNOTE-811 study of trastuzumab and chemotherapy with or without pembrolizumab for HER2-positive metastatic gastric or gastroesophageal junction (G/GEJ) cancer. Ann Oncol. 2021. https://doi.org/10.1016/j.annonc.2021.06.011.

58. Moehler M, Shitara K, Garrido M, Salman P, Shen L, Wyrwicz L, et al. LBA6_PR Nivolumab (nivo) plus chemotherapy (chemo) versus chemo as first-line (1L) treatment for advanced gastric cancer/gastroesophageal junction cancer (GC/GEJC)/esophageal adenocarcinoma (EAC): first results of the CheckMate 649 study. Ann Oncol. 2020. https://doi. org/10.1016/j.annonc.2020.08.2296.

59. Yang Y, Wang Z, Fang J, Yu Q, Han B, Cang S, et al. Efficacy and safety of Sintilimab plus Pemetrexed and platinum as first-line treatment for locally advanced or metastatic nonsquamous NSCLC: a randomized, double-blind, phase 3 study (oncology pRogram by InnovENT antiPD-1-11). J Thorac Oncol. 2020;15:1636-46. 
60. Zhou C, Wu L, Fan Y, Wang Z, Liu L, Chen G, et al. Sintilimab plus platinum and gemcitabine as first-line treatment for advanced or metastatic squamous NSCLC: results from a randomized, double-blind, phase 3 trial (ORIENT-12). J Thorac Oncol. 2021;16:1501-11.

61. Zhou C, Chen G, Huang Y, Zhou J, Lin L, Feng J, et al. Camrelizumab plus carboplatin and pemetrexed versus chemotherapy alone in chemotherapy-naive patients with advanced non-squamous non-small-cell lung cancer (CameL): a randomised, open-label, multicentre, phase 3 trial. Lancet Respir Med. 2021;9:305-14.

62. Yang Y, Qu S, Li J, Hu C, Xu M, Li W, et al. Camrelizumab versus placebo in combination with gemcitabine and cisplatin as first-line treatment for recurrent or metastatic nasopharyngeal carcinoma (CAPTAIN-1st): a multicentre, randomised, double-blind, phase 3 trial. Lancet Oncol. 2021;22:1162-74.

63. Wang J, Lu S, Yu X, Hu Y, Sun Y, Wang Z, et al. Tislelizumab plus chemotherapy vs chemotherapy alone as first-line treatment for advanced squamous non-small-cell lung Cancer: a phase 3 randomized clinical trial. JAMA Oncol. 2021;7:709-17.

64. Lu S, Wang J, Yu Y, Yu X, Hu Y, Ai X, et al. Tislelizumab plus chemotherapy as first-line treatment for locally advanced or metastatic nonsquamous NSCLC (RATIONALE 304): a randomized phase 3 trial. J Thorac Oncol. 2021;16:1512-22.

65. Socinski MA, Jotte RM, Cappuzzo F, Orlandi F, Stroyakovskiy D, Nogami $\mathrm{N}$, et al. Atezolizumab for first-line treatment of metastatic nonsquamous NSCLC. N Engl J Med. 2018;378:2288-301.

66. Schmid P, Rugo HS, Adams S, Schneeweiss A, Barrios $\mathrm{CH}$, Iwata $\mathrm{H}$, et al. Atezolizumab plus nab-paclitaxel as first-line treatment for unresectable, locally advanced or metastatic triple-negative breast cancer (IMpassion 130): updated efficacy results from a randomised, doubleblind, placebo-controlled, phase 3 trial. Lancet Oncol. 2020;21:44-59.

67. Mansfield AS, Każarnowicz A, Karaseva N, Sánchez A, De Boer R, Andric Z, et al. Safety and patient-reported outcomes of atezolizumab, carboplatin, and etoposide in extensive-stage small-cell lung cancer (IMpower133): a randomized phase I/III trial. Ann Oncol. 2020;31:310-7.

68. West H, McCleod M, Hussein M, Morabito A, Rittmeyer A, Conter HJ, et al. Atezolizumab in combination with carboplatin plus nab-paclitaxel chemotherapy compared with chemotherapy alone as first-line treatment for metastatic non-squamous non-small-cell lung cancer (IMpower130): a multicentre, randomised, open-label, phase 3 trial. Lancet Oncol. 2019;20:924-37.

69. Paz-Ares L, Dvorkin M, Chen Y, Reinmuth N, Hotta K, Trukhin D, et al. Durvalumab plus platinum-etoposide versus platinum-etoposide in first-line treatment of extensive-stage small-cell lung cancer (CASPIAN): a randomised, controlled, open-label, phase 3 trial. Lancet. 2019;394:1929-39.

70. Hwang WL, Pike LRG, Royce TJ, Mahal BA, Loeffler JS. Safety of combining radiotherapy with immune-checkpoint inhibition. Nat Rev Clin Oncol. 2018;15:477-94.

71. Liu Y, Dong Y, Kong L, Shi F, Zhu H, Yu J. Abscopal effect of radiotherapy combined with immune checkpoint inhibitors. J Hematol Oncol. 2018;11:104.

72. Lim JY, Gerber SA, Murphy SP, Lord EM. Type I interferons induced by radiation therapy mediate recruitment and effector function of CD8(+) T cells. Cancer Immunol Immunother. 2014;63:259-71.

73. Twyman-Saint Victor C, Rech AJ, Maity A, Rengan R, Pauken KE, Stelekati $E$, et al. Radiation and dual checkpoint blockade activate non-redundant immune mechanisms in cancer. Nature. 2015;520:373-7.

74. Deng L, Liang H, Burnette B, Beckett M, Darga T, Weichselbaum RR, et al. Irradiation and anti-PD-L1 treatment synergistically promote antitumor immunity in mice. J Clin Invest. 2014;124:687-95.

75. Wang X, Schoenhals JE, Li A, Valdecanas DR, Ye H, Zang F, et al. Suppression of type I IFN signaling in tumors mediates resistance to anti-PD-1 treatment that can be overcome by radiotherapy. Cancer Res. 2017;77:839-50

76. Kordbacheh T, Honeychurch J, Blackhall F, Faivre-Finn C, Illidge T. Radiotherapy and anti-PD-1/PD-L1 combinations in lung cancer: building better translational research platforms. Ann Oncol. 2018;29:301-10.

77. Tree AC, Khoo VS, Eeles RA, Ahmed M, Dearnaley DP, Hawkins MA, et al. Stereotactic body radiotherapy for oligometastases. Lancet Oncol. 2013;14:e28-37.
78. Jabbour SK, Berman AT, Decker RH, Lin Y, Feigenberg SJ, Gettinger SN, et al. Phase 1 trial of Pembrolizumab administered concurrently with Chemoradiotherapy for locally advanced non-small cell lung Cancer: a nonrandomized controlled trial. JAMA Oncol. 2020;6:848-55.

79. Powell SF, Gold KA, Gitau MM, Sumey CJ, Lohr MM, McGraw SC, et al. Safety and efficacy of Pembrolizumab with Chemoradiotherapy in locally advanced head and neck squamous cell carcinoma: a phase IB study. J Clin Oncol. 2020;38:2427-37.

80. Peters S, Felip E, Dafni U, Belka C, Guckenberger M, Irigoyen A, et al. Safety evaluation of nivolumab added concurrently to radiotherapy in a standard first line chemo-radiotherapy regimen in stage III non-small cell lung cancer-the ETOP NICOLAS trial. Lung Cancer. 2019;133:83-7.

81. Papadopoulos KP, Johnson ML, Lockhart AC, Moore K, Falchook GS, Formenti SC, et al. First-in-human study of Cemiplimab alone or in combination with radiotherapy and/or low-dose cyclophosphamide in patients with advanced malignancies. Clin Cancer Res. 2020;26:1025-33.

82. Welsh JW, Heymach JV, Guo C, Menon H, Klein K, Cushman TR, et al. Phase 1/2 trial of Pembrolizumab and concurrent Chemoradiation therapy for limited-stage SCLC. J Thorac Oncol. 2020;15:1919-27.

83. Altorki NK, McGraw TE, Borczuk AC, Saxena A, Port JL, Stiles BM, et al. Neoadjuvant durvalumab with or without stereotactic body radiotherapy in patients with early-stage non-small-cell lung cancer: a single-Centre, randomised phase 2 trial. Lancet Oncol. 2021;22:824-35.

84. Antonia SJ, Villegas A, Daniel D, Vicente D, Murakami S, Hui R, et al. Overall survival with Durvalumab after Chemoradiotherapy in stage III NSCLC. N Engl J Med. 2018;379:2342-50.

85. McBride S, Sherman E, Tsai CJ, Baxi S, Aghalar J, Eng J, et al. Randomized phase II trial of Nivolumab with stereotactic body radiotherapy versus Nivolumab alone in metastatic head and neck squamous cell carcinoma. J Clin Oncol. 2021;39:30-7.

86. Lee NY, Ferris RL, Psyrri A, Haddad RI, Tahara M, Bourhis J, et al. Avelumab plus standard-of-care chemoradiotherapy versus chemoradiotherapy alone in patients with locally advanced squamous cell carcinoma of the head and neck: a randomised, double-blind, placebocontrolled, multicentre, phase 3 trial. Lancet Oncol. 2021;22:450-62.

87. Kerbel RS. Tumor angiogenesis. N Engl J Med. 2008;358:2039-49.

88. Qin S, Yi M, Jiao D, Li A, Wu K. Distinct roles of VEGFA and ANGPT2 in lung adenocarcinoma and squamous cell carcinoma. J Cancer. 2020;11:153-67.

89. Böckelmann LC, Schumacher U. Targeting tumor interstitial fluid pressure: will it yield novel successful therapies for solid tumors? Expert Opin Ther Targets. 2019;23:1005-14.

90. Lee WS, Yang H, Chon HJ, Kim C. Combination of anti-angiogenic therapy and immune checkpoint blockade normalizes vascularimmune crosstalk to potentiate cancer immunity. Exp Mol Med. 2020;52:1475-85.

91. Voron T, Colussi O, Marcheteau E, Pernot S, Nizard M, Pointet AL, et al. VEGF-A modulates expression of inhibitory checkpoints on CD8+ T cells in tumors. J Exp Med. 2015;212:139-48.

92. Terme M, Pernot S, Marcheteau E, Sandoval F, Benhamouda N, Colussi $O$, et al. VEGFA-VEGFR pathway blockade inhibits tumor-induced regulatory T-cell proliferation in colorectal cancer. Cancer Res. 2013;73:539-49.

93. Bourhis M, Palle J, Galy-Fauroux I, Terme M. Direct and indirect modulation of T cells by VEGF-A counteracted by anti-Angiogenic treatment. Front Immunol. 2021;12:616837.

94. De Palma M, Venneri MA, Galli R, Sergi Sergi L, Politi LS, Sampaolesi $M$, et al. Tie2 identifies a hematopoietic lineage of proangiogenic monocytes required for tumor vessel formation and a mesenchymal population of pericyte progenitors. Cancer Cell. 2005;8:211-26.

95. Coffelt SB, Tal AO, Scholz A, De Palma M, Patel S, Urbich C, et al. Angiopoietin-2 regulates gene expression in TIE2-expressing monocytes and augments their inherent proangiogenic functions. Cancer Res. 2010;70:5270-80.

96. Coffelt SB, Chen YY, Muthana M, Welford AF, Tal AO, Scholz A, et al. Angiopoietin 2 stimulates TIE2-expressing monocytes to suppress T cell activation and to promote regulatory $\mathrm{T}$ cell expansion. J Immunol. 2011;186:4183-90.

97. Rahma OE, Hodi FS. The intersection between tumor angiogenesis and immune suppression. Clin Cancer Res. 2019;25:5449-57. 
98. Chen W, Shen L, Jiang J, Zhang L, Zhang Z, Pan J, et al. Antiangiogenic therapy reverses the immunosuppressive breast cancer microenvironment. Biomark Res. 2021:9:59.

99. Jain RK. Molecular regulation of vessel maturation. Nat Med. 2003;9:685-93.

100. Viallard C, Larrivée B. Tumor angiogenesis and vascular normalization: alternative therapeutic targets. Angiogenesis. 2017;20:409-26.

101. Pan C, Liu H, Robins E, Song W, Liu D, Li Z, et al. Next-generation immuno-oncology agents: current momentum shifts in cancer immunotherapy. J Hematol Oncol. 2020;13:29.

102. Huang Y, Yuan J, Righi E, Kamoun WS, Ancukiewicz M, Nezivar J, et al. Vascular normalizing doses of antiangiogenic treatment reprogram the immunosuppressive tumor microenvironment and enhance immunotherapy. Proc Natl Acad Sci U S A. 2012;109:17561-6.

103. Du Four S, Maenhout SK, Niclou SP, Thielemans K, Neyns B, Aerts JL. Combined VEGFR and CTLA-4 blockade increases the antigen-presenting function of intratumoral DCs and reduces the suppressive capacity of intratumoral MDSCs. Am J Cancer Res. 2016;6:2514-31.

104. Horikawa N, Abiko K, Matsumura N, Hamanishi J, Baba T, Yamaguchi K, et al. Expression of vascular endothelial growth factor in ovarian Cancer inhibits tumor immunity through the accumulation of myeloid-derived suppressor cells. Clin Cancer Res. 2017;23:587-99.

105. Noman MZ, Desantis G, Janji B, Hasmim M, Karray S, Dessen P, et al. PD-L1 is a novel direct target of HIF-1a, and its blockade under hypoxia enhanced MDSC-mediated T cell activation. J Exp Med. 2014;211:781-90.

106. Wu FTH, Xu P, Chow A, Man S, Krüger J, Khan KA, et al. Pre- and postoperative anti-PD-L1 plus anti-angiogenic therapies in mouse breast or renal cancer models of micro- or macro-metastatic disease. Br J Cancer. 2019;120:196-206

107. Schmittnaegel M, Rigamonti N, Kadioglu E, Cassará A, Wyser Rmili C, Kiialainen $A$, et al. Dual angiopoietin-2 and VEGFA inhibition elicits antitumor immunity that is enhanced by PD-1 checkpoint blockade. Sci Transl Med. 2017;9:eaak9670.

108. Allen E, Jabouille A, Rivera LB, Lodewijckx I, Missiaen R, Steri V, et al. Combined antiangiogenic and anti-PD-L1 therapy stimulates tumor immunity through HEV formation. Sci Transl Med. 2017;9:eaak9679.

109. Powles T, Plimack ER, Soulières D, Waddell T, Stus V, Gafanov R, et al. Pembrolizumab plus axitinib versus sunitinib monotherapy as first-line treatment of advanced renal cell carcinoma (KEYNOTE-426): extended follow-up from a randomised, open-label, phase 3 trial. Lancet Oncol. 2020:21:1563-73.

110. Makker V, Rasco D, Vogelzang NJ, Brose MS, Cohn AL, Mier J, et al. Lenvatinib plus pembrolizumab in patients with advanced endometrial cancer: an interim analysis of a multicentre, open-label, single-arm, phase 2 trial. Lancet Oncol. 2019;20:711-8.

111. Finn RS, Qin S, Ikeda M, Galle PR, Ducreux M, Kim TY, et al. Atezolizumab plus Bevacizumab in Unresectable Hepatocellular Carcinoma. N Engl J Med. 2020;382:1894-905.

112. Choueiri TK, Powles T, Burotto M, Escudier B, Bourlon MT, Zurawski B, et al. Nivolumab plus Cabozantinib versus Sunitinib for advanced renalcell carcinoma. N Engl J Med. 2021;384:829-41.

113. Motzer RJ, Robbins PB, Powles T, Albiges L, Haanen JB, Larkin J, et al. Avelumab plus axitinib versus sunitinib in advanced renal cell carcinoma: biomarker analysis of the phase 3 JAVELIN renal 101 trial. Nat Med. 2020;26:1733-41.

114. Xie L, Xu J, Sun X, Guo W, Gu J, Liu K, et al. Apatinib plus camrelizumab (anti-PD1 therapy, SHR-1210) for advanced osteosarcoma (APFAO) progressing after chemotherapy: a single-arm, open-label, phase 2 trial. J Immunother Cancer. 2020;8:e000798

115. Liu J, Liu Q, Li Y, Li Q, Su F, Yao H, et al. Efficacy and safety of camrelizumab combined with apatinib in advanced triple-negative breast cancer: an open-label phase II trial. J Immunother Cancer. 2020;8:e000696.

116. Lan C, Shen J, Wang Y, Li J, Liu Z, He M, et al. Camrelizumab plus Apatinib in patients with advanced cervical Cancer (CLAP): a multicenter, open-label, single-arm, Phase II Trial. J Clin Oncol. 2020;38:4095-106.

117. Fan Y, Zhao J, Wang Q, Huang D, Li X, Chen J, et al. Camrelizumab plus Apatinib in extensive-stage SCLC (PASSION): a multicenter, two-stage, phase 2 trial. J Thorac Oncol. 2021;16:299-309.
118. Chu T, Zhong R, Zhong H, Zhang B, Zhang W, Shi C, et al. Phase $1 \mathrm{~b}$ study of Sintilimab plus Anlotinib as first-line therapy in patients with advanced NSCLC. J Thorac Oncol. 2021;16:643-52.

119. Ren Z, Xu J, Bai Y, Xu A, Cang S, Du C, et al. Sintilimab plus a bevacizumab biosimilar (IBI305) versus sorafenib in unresectable hepatocellular carcinoma (ORIENT-32): a randomised, open-label, phase 2-3 study. Lancet Oncol. 2021;22:977-90.

120. Sheng X, Yan X, Chi Z, Si L, Cui C, Tang B, et al. Axitinib in combination with Toripalimab, a humanized immunoglobulin G(4) monoclonal antibody against programmed cell Death-1, in patients with metastatic mucosal melanoma: an open-label phase IB trial. J Clin Oncol. 2019;37:2987-99.

121. Egen JG, Kuhns MS, Allison JP. CTLA-4: new insights into its biological function and use in tumor immunotherapy. Nat Immunol. 2002;3:611-8

122. Choi JM, Ahn MH, Chae WJ, Jung YG, Park JC, Song HM, et al. Intranasal delivery of the cytoplasmic domain of CTLA-4 using a novel protein transduction domain prevents allergic inflammation. Nat Med. 2006;12:574-9.

123. Parry RV, Chemnitz JM, Frauwirth KA, Lanfranco AR, Braunstein I, Kobayashi SV, et al. CTLA-4 and PD-1 receptors inhibit T-cell activation by distinct mechanisms. Mol Cell Biol. 2005;25:9543-53.

124. Lee KM, Chuang E, Griffin M, Khattri R, Hong DK, Zhang W, et al. Molecular basis of T cell inactivation by CTLA-4. Science. 1998;282:2263-6.

125. Qureshi OS, Zheng Y, Nakamura K, Attridge K, Manzotti C, Schmidt EM, et al. Trans-endocytosis of CD80 and CD86: a molecular basis for the cell-extrinsic function of CTLA-4. Science. 2011:332:600-3.

126. Lingel $H$, Brunner-Weinzierl MC. CTLA-4 (CD152): a versatile receptor for immune-based therapy. Semin Immunol. 2019:42:101298.

127. Wolchok JD, Neyns B, Linette G, Negrier S, Lutzky J, Thomas L, et al. Ipilimumab monotherapy in patients with pretreated advanced melanoma: a randomised, double-blind, multicentre, phase 2, dose-ranging study. Lancet Oncol. 2010;11:155-64.

128. Romano E, Kusio-Kobialka M, Foukas PG, Baumgaertner P, Meyer C, Ballabeni P, et al. Ipilimumab-dependent cell-mediated cytotoxicity of regulatory T cells ex vivo by nonclassical monocytes in melanoma patients. Proc Natl Acad Sci U S A. 2015;112:6140-5.

129. Simpson TR, Li F, Montalvo-Ortiz W, Sepulveda MA, Bergerhoff K, Arce $F$, et al. Fc-dependent depletion of tumor-infiltrating regulatory $T$ cells co-defines the efficacy of anti-CTLA-4 therapy against melanoma. J Exp Med. 2013;210:1695-710.

130. Arce Vargas F, Furness AJS, Litchfield K, Joshi K, Rosenthal R, Ghorani $E$, et al. Fc effector function contributes to the activity of human antiCTLA-4 antibodies. Cancer Cell. 2018;33:649-63.e4.

131. Wu K, Yi M, Qin S, Chu Q, Zheng X, Wu K. The efficacy and safety of combination of PD-1 and CTLA-4 inhibitors: a meta-analysis. Exp Hematol Oncol. 2019;8:26

132. Hodi FS, Chesney J, Pavlick AC, Robert C, Grossmann KF, McDermott DF, et al. Combined nivolumab and ipilimumab versus ipilimumab alone in patients with advanced melanoma: 2-year overall survival outcomes in a multicentre, randomised, controlled, phase 2 trial. Lancet Oncol. 2016:17:1558-68.

133. Larkin J, Chiarion-Sileni V, Gonzalez R, Grob JJ, Rutkowski P, Lao CD, et al. Five-year survival with combined Nivolumab and Ipilimumab in advanced melanoma. N Engl J Med. 2019;381:1535-46.

134. Overman MJ, Lonardi S, Wong KYM, Lenz HJ, Gelsomino F, Aglietta M, et al. Durable clinical benefit with Nivolumab plus Ipilimumab in DNA mismatch repair-deficient/microsatellite instability-high metastatic colorectal Cancer. J Clin Oncol. 2018;36:773-9.

135. Motzer RJ, Rini BI, McDermott DF, Arén Frontera O, Hammers HJ, Carducci MA, et al. Nivolumab plus ipilimumab versus sunitinib in first-line treatment for advanced renal cell carcinoma: extended follow-up of efficacy and safety results from a randomised, controlled, phase 3 trial. Lancet Oncol. 2019:20:1370-85.

136. Hellmann MD, Paz-Ares L, Bernabe Caro R, Zurawski B, Kim SW, Carcereny Costa E, et al. Nivolumab plus Ipilimumab in advanced non-smallcell lung Cancer. N Engl J Med. 2019;381:2020-31.

137. Baas P, Scherpereel A, Nowak AK, Fujimoto N, Peters S, Tsao AS, et al. First-line nivolumab plus ipilimumab in unresectable malignant pleural mesothelioma (CheckMate 743): a multicentre, randomised, open-label, phase 3 trial. Lancet. 2021;397:375-86. 
138. Yau T, Kang YK, Kim TY, El-Khoueiry AB, Santoro A, Sangro B, et al. Efficacy and safety of Nivolumab plus Ipilimumab in patients with advanced hepatocellular carcinoma previously treated with Sorafenib: the CheckMate 040 randomized clinical trial. JAMA Oncol. 2020;6:e204564

139. Ribas A. Clinical development of the anti-CTLA-4 antibody tremelimumab. Semin Oncol. 2010;37:450-4.

140. Goldman JW, Dvorkin M, Chen Y, Reinmuth N, Hotta K, Trukhin D, et al. Durvalumab, with or without tremelimumab, plus platinumetoposide versus platinum-etoposide alone in first-line treatment of extensive-stage small-cell lung cancer (CASPIAN): updated results from a randomised, controlled, open-label, phase 3 trial. Lancet Oncol. 2021:22:51-65.

141. Gao J, Navai N, Alhalabi O, Siefker-Radtke A, Campbell MT, Tidwell RS, et al. Neoadjuvant PD-L1 plus CTLA-4 blockade in patients with cisplatin-ineligible operable high-risk urothelial carcinoma. Nat Med. 2020;26:1845-51.

142. Powles T, van der Heijden MS, Castellano D, Galsky MD, Loriot Y, Petrylak DP, et al. Durvalumab alone and durvalumab plus tremelimumab versus chemotherapy in previously untreated patients with unresectable, locally advanced or metastatic urothelial carcinoma (DANUBE): a randomised, open-label, multicentre, phase 3 trial. Lancet Oncol. 2020;21:1574-88.

143. Chen EX, Jonker DJ, Loree JM, Kennecke HF, Berry SR, Couture F, et al. Effect of combined immune checkpoint inhibition vs best supportive care alone in patients with advanced colorectal Cancer: the Canadian Cancer trials group CO.26 study. JAMA Oncol. 2020;6:831-8.

144. Ferris RL, Haddad R, Even C, Tahara M, Dvorkin M, Ciuleanu TE, et al. Durvalumab with or without tremelimumab in patients with recurrent or metastatic head and neck squamous cell carcinoma: EAGLE, a randomized, open-label phase III study. Ann Oncol. 2020;31:942-50.

145. Rizvi NA, Cho BC, Reinmuth N, Lee KH, Luft A, Ahn MJ, et al. Durvalumab with or without Tremelimumab vs standard chemotherapy in first-line treatment of metastatic non-small cell lung Cancer: the MYSTIC phase 3 randomized clinical trial. JAMA Oncol. 2020;6:661-74.

146. Planchard D, Reinmuth N, Orlov S, Fischer JR, Sugawara S, Mandziuk S, et al. ARCTIC: durvalumab with or without tremelimumab as third-line or later treatment of metastatic non-small-cell lung cancer. Ann Oncol. 2020;31:609-18.

147. Kelly RJ, Lee J, Bang YJ, Almhanna K, Blum-Murphy M, Catenacci DVT, et al. Safety and efficacy of Durvalumab and Tremelimumab alone or in combination in patients with advanced gastric and Gastroesophageal junction adenocarcinoma. Clin Cancer Res. 2020;26:846-54.

148. Siu LL, Even C, Mesía R, Remenar E, Daste A, Delord JP, et al. Safety and efficacy of Durvalumab with or without Tremelimumab in patients with PD-L1-low/negative recurrent or metastatic HNSCC: the phase 2 CONDOR randomized clinical trial. JAMA Oncol. 2019:5:195-203.

149. Necchi A, Giannatempo P, Raggi D, Mariani L, Colecchia M, Farè E, et al. An open-label randomized phase 2 study of Durvalumab alone or in combination with Tremelimumab in patients with advanced germ cell tumors (APACHE): results from the first planned interim analysis. Eur Urol. 2019;75:201-3.

150. Calabrò L, Morra A, Giannarelli D, Amato G, D'Incecco A, Covre A, et al. Tremelimumab combined with durvalumab in patients with mesothelioma (NIBIT-MESO-1): an open-label, non-randomised, phase 2 study. Lancet Respir Med. 2018;6:451-60.

151. O'Reilly EM, Oh DY, Dhani N, Renouf DJ, Lee MA, Sun W, et al. Durvalumab with or without Tremelimumab for patients with metastatic pancreatic ductal adenocarcinoma: a phase 2 randomized clinical trial. JAMA Oncol. 2019:5:1431-8.

152. Kelley RK, Sangro B, Harris W, Ikeda M, Okusaka T, Kang YK, et al. Safety, efficacy, and pharmacodynamics of Tremelimumab plus Durvalumab for patients with Unresectable hepatocellular carcinoma: randomized expansion of a phase I/II study. J Clin Oncol. 2021;39:2991-3001.

153. Postow MA, Sidlow R, Hellmann MD. Immune-related adverse events associated with immune checkpoint blockade. N Engl J Med. 2018;378:158-68.

154. Larkin J, Chiarion-Sileni V, Gonzalez R, Grob JJ, Cowey CL, Lao CD, et al. Combined Nivolumab and Ipilimumab or Monotherapy in untreated melanoma. N Engl J Med. 2015;373:23-34.
155. Perez-Ruiz E, Minute L, Otano I, Alvarez M, Ochoa MC, Belsue V, et al. Prophylactic TNF blockade uncouples efficacy and toxicity in dual CTLA-4 and PD-1 immunotherapy. Nature. 2019;569:428-32.

156. Zhu C, Anderson AC, Schubart A, Xiong H, Imitola J, Khoury SJ, et al. The Tim-3 ligand galectin-9 negatively regulates T helper type 1 immunity. Nat Immunol. 2005;6:1245-52.

157. Sakuishi K, Apetoh L, Sullivan JM, Blazar BR, Kuchroo VK, Anderson AC Targeting Tim-3 and PD-1 pathways to reverse T cell exhaustion and restore anti-tumor immunity. J Exp Med. 2010;207:2187-94.

158. Harding JJ, Moreno V, Bang YJ, Hong MH, Patnaik A, Trigo J, et al. Blocking TIM-3 in treatment-refractory advanced solid tumors: a phase la/b study of LY3321367 with or without an anti-PD-L1 antibody. Clin Cancer Res. 2021:27:2168-78.

159. Hollebecque A, Chung HC, de Miguel MJ, Italiano A, Machiels JP, Lin CC, et al. Safety and antitumor activity of a-PD-L1 antibody as monotherapy or in combination with a-TIM-3 antibody in patients with microsatellite instability-high/mismatch repair-deficient tumors. Clin Cancer Res. 2021. https://doi.org/10.1158/1078-0432.CCR-21-0261.

160. Curigliano G, Gelderblom H, Mach N, Doi T, Tai D, Forde PM, et al. Phase I/lb clinical trial of Sabatolimab, an anti-TIM-3 antibody, alone and in combination with Spartalizumab, an anti-PD-1 antibody, in advanced solid tumors. Clin Cancer Res. 2021;27:3620-9.

161. Gestermann N, Saugy D, Martignier C, Tillé L, Fuertes Marraco SA, Zettl M, et al. LAG-3 and PD-1+LAG-3 inhibition promote anti-tumor immune responses in human autologous melanoma/T cell co-cultures. Oncoimmunology. 2020;9:1736792.

162. Li Y, Zhang Y, Cao G, Zheng X, Sun C, Wei H, et al. Blockade of checkpoint receptor PVRIG unleashes anti-tumor immunity of NK cells in murine and human solid tumors. J Hematol Oncol. 2021;14:100.

163. Mao L, Xiao Y, Yang QC, Yang SC, Yang LL, Sun ZJ. TIGIT/CD155 blockade enhances anti-PD-L1 therapy in head and neck squamous cell carcinoma by targeting myeloid-derived suppressor cells. Oral Oncol. 2021;121:105472.

164. Xiao N, Zhu X, Li K, Chen Y, Liu X, Xu B, et al. Blocking siglec-10(hi) tumor-associated macrophages improves anti-tumor immunity and enhances immunotherapy for hepatocellular carcinoma. Exp Hematol Oncol. 2021;10:36

165. Lipson EJ, Tawbi HA-H, Schadendorf D, Ascierto PA, Matamala L, Gutiérrez EC, et al. Relatlimab (RELA) plus nivolumab (NIVO) versus NIVO in first-line advanced melanoma: primary phase III results from RELATIVITY-047 (CA224-047). J Clin Oncol. 2021. https://doi.org/10.1200/JCO. 2021.39 .15 suppl.9503.

166. Vaena DA, Fleming GF, Chmielowski B, Sharma M, Hamilton EP, Sullivan $\mathrm{RJ}$, et al. COM701 with or without nivolumab: results of an ongoing phase 1 study of safety, tolerability and preliminary antitumor activity in patients with advanced solid malignancies (NCT03667716). J Clin Oncol. 2021. https://doi.org/10.1200/JCO.2021.39.15 suppl.2504.

167. Rodriguez-Abreu D, Johnson ML, Hussein MA, Cobo M, Patel AJ, Secen NM, et al. Primary analysis of a randomized, double-blind, phase II study of the anti-TIGIT antibody tiragolumab (tira) plus atezolizumab (atezo) versus placebo plus atezo as first-line (1L) treatment in patients with PD-L1-selected NSCLC (CITYSCAPE). J Clin Oncol. 2020. https://doi.org/ 10.1200/JCO.2020.38.15 suppl.9503.

168. Marin-Acevedo JA, Kimbrough EO, Manochakian R, Zhao Y, Lou Y. Immunotherapies targeting stimulatory pathways and beyond. J Hematol Oncol. 2021;14:78.

169. Pourakbari R, Hajizadeh F, Parhizkar F, Aghebati-Maleki A, Mansouri S, Aghebati-Maleki L. Co-stimulatory agonists: an insight into the immunotherapy of cancer. EXCLI J. 2021;20:1055-85.

170. McGray AJR, Eppolito C, Miliotto A, Singel KL, Stephenson K, Lugade A, et al. A prime/boost vaccine platform efficiently identifies CD27 agonism and depletion of myeloid-derived suppressor cells as therapies that rationally combine with checkpoint blockade in ovarian cancer. Cancer Immunol Immunother. 2021:70:3451-60.

171. Buchan SL, Fallatah M, Thirdborough SM, Taraban VY, Rogel A, Thomas LJ, et al. PD-1 blockade and CD27 stimulation activate distinct transcriptional programs that synergize for CD8(+) T-cell-driven antitumor immunity. Clin Cancer Res. 2018;24:2383-94.

172. Diggs LP, Ruf B, Ma C, Heinrich B, Cui L, Zhang Q, et al. CD40-mediated immune cell activation enhances response to anti-PD-1 in murine intrahepatic cholangiocarcinoma. J Hepatol. 2021;74:1145-54. 
173. Qu QX, Zhu XY, Du WW, Wang HB, Shen Y, Zhu YB, et al. 4-1BB Agonism combined with PD-L1 blockade increases the number of tissueresident CD8+ T cells and facilitates tumor abrogation. Front Immunol. 2020;11:577.

174. Ma Y, Li J, Wang H, Chiu Y, Kingsley CV, Fry D, et al. Combination of PD-1 inhibitor and OX40 agonist induces tumor rejection and immune memory in mouse models of pancreatic Cancer. Gastroenterology. 2020;159:306-19.e12.

175. Wang B, Zhang W, Jankovic V, Golubov J, Poon P, Oswald EM, et al. Combination cancer immunotherapy targeting PD-1 and GITR can rescue $\mathrm{CD} 8(+) \mathrm{T}$ cell dysfunction and maintain memory phenotype. Sci Immunol. 2018;3:eaat7061.

176. Hanson A, Elpek K, Duong E, Shallberg L, Fan M, Johnson C, et al. ICOS agonism by JTX-2011 (vopratelimab) requires initial T cell priming and fc cross-linking for optimal T cell activation and anti-tumor immunity in preclinical models. PLoS One. 2020;15:e0239595.

177. Patel MR, Naing A III, HAB, Lin C-C, Curigliano G, Thistlethwaite F, et al. A phase $1 / 2$ open-label study of $\mathrm{KY} 1044$, an anti-ICOS antibody with dual mechanism of action, as single agent and in combination with atezolizumab, in adult patients with advanced malignancies. J Clin Oncol. 2021. https://doi.org/10.1200/JCO.2021.39.15_suppl.2624.

178. Weiss SA, Djureinovic D, Jessel S, Krykbaeva I, Zhang L, Jilaveanu L, et al. A phase I study of APX005M and Cabiralizumab with or without Nivolumab in patients with melanoma, kidney Cancer, or nonsmall cell lung Cancer resistant to anti-PD-1/PD-L1. Clin Cancer Res. 2021;27:4757-67.

179. Tolcher AW, Sznol M, Hu-Lieskovan S, Papadopoulos KP, Patnaik A, Rasco DW, et al. Phase Ib study of Utomilumab (PF-05082566), a 4-1BB/CD137 agonist, in combination with Pembrolizumab (MK-3475) in patients with advanced solid tumors. Clin Cancer Res. 2017;23:5349-57.

180. Piha-Paul SA, Geva R, Tan TJ, Lim DW, Hierro C, Doi T, et al. First-inhuman phase l/lb open-label dose-escalation study of GWN323 (anti-GITR) as a single agent and in combination with spartalizumab (anti-PD-1) in patients with advanced solid tumors and lymphomas. J Immunother Cancer. 2021;9:e002863.

181. Yarden Y, Sliwkowski MX. Untangling the ErbB signalling network. Nat Rev Mol Cell Biol. 2001;2:127-37.

182. Liu Q, Yu S, Zhao W, Qin S, Chu Q, Wu K. EGFR-TKIs resistance via EGFRindependent signaling pathways. Mol Cancer. 2018;17:53.

183. Recondo G, Facchinetti F, Olaussen KA, Besse B, Friboulet L. Making the first move in EGFR-driven or ALK-driven NSCLC: first-generation or nextgeneration TKI? Nat Rev Clin Oncol. 2018;15:694-708.

184. Qiao M, Jiang T, Liu X, Mao S, Zhou F, Li X, et al. Immune checkpoint inhibitors in EGFR-mutated NSCLC: dusk or Dawn? J Thorac Oncol. 2021;16:1267-88

185. Lisberg A, Cummings A, Goldman JW, Bornazyan K, Reese N, Wang T, et al. A phase Il study of Pembrolizumab in EGFR-mutant, PD-L1+, tyrosine kinase inhibitor Naiive patients with advanced NSCLC. J Thorac Oncol. 2018;13:1138-45.

186. Huang MY, Jiang XM, Wang BL, Sun Y, Lu JJ. Combination therapy with PD-1/PD-L1 blockade in non-small cell lung cancer: strategies and mechanisms. Pharmacol Ther. 2021;219:107694.

187. Sugiyama E, Togashi Y, Takeuchi Y, Shinya S, Tada Y, Kataoka K, et al. Blockade of EGFR improves responsiveness to PD-1 blockade in EGFRmutated non-small cell lung cancer. Sci Immunol. 2020;5:eaav3937.

188. Yi M, Niu M, Xu L, Luo S, Wu K. Regulation of PD-L1 expression in the tumor microenvironment. J Hematol Oncol. 2021;14:10.

189. Gettinger S, Hellmann MD, Chow LQM, Borghaei H, Antonia S, Brahmer $J R$, et al. Nivolumab plus Erlotinib in patients with EGFR-mutant advanced NSCLC. J Thorac Oncol. 2018;13:1363-72.

190. Rudin C, Cervantes A, Dowlati A, Besse B, Ma B, Costa D, et al. P3.02C-046 safety, clinical activity and biomarker results from a phase Ib study of Erlotinib plus Atezolizumab in advanced NSCLC. JThorac Oncol. 2017. https://doi.org/10.1016/j.jtho.2016.11.1841.

191. Oshima Y, Tanimoto T, Yuji K, Tojo A. EGFR-TKI-associated interstitial pneumonitis in Nivolumab-treated patients with non-small cell lung Cancer. JAMA Oncol. 2018:4:1112-5.

192. Oxnard GR, Yang JC, Yu H, Kim SW, Saka H, Horn L, et al. TATTON: a multi-arm, phase Ib trial of osimertinib combined with selumetinib, savolitinib, or durvalumab in EGFR-mutant lung cancer. Ann Oncol. 2020;31:507-16.
193. Yang JC, Shepherd FA, Kim DW, Lee GW, Lee JS, Chang GC, et al. Osimertinib plus Durvalumab versus Osimertinib Monotherapy in EGFR T790M-positive NSCLC following previous EGFR TKI therapy: CAURAL brief report. J Thorac Oncol. 2019;14:933-9.

194. Schoenfeld AJ, Arbour KC, Rizvi H, Iqbal AN, Gadgeel SM, Girshman J, et al. Severe immune-related adverse events are common with sequential PD-(L)1 blockade and osimertinib. Ann Oncol. 2019;30:839-44.

195. Iwahara T, Fujimoto J, Wen D, Cupples R, Bucay N, Arakawa T, et al. Molecular characterization of ALK, a receptor tyrosine kinase expressed specifically in the nervous system. Oncogene. 1997;14:439-49.

196. Katayama R, Lovly CM, Shaw AT. Therapeutic targeting of anaplastic lymphoma kinase in lung cancer: a paradigm for precision cancer medicine. Clin Cancer Res. 2015;21:2227-35.

197. Golding B, Luu A, Jones R, Viloria-Petit AM. The function and therapeutic targeting of anaplastic lymphoma kinase (ALK) in non-small cell lung cancer (NSCLC). Mol Cancer. 2018;17:52.

198. Shaw AT, Bauer TM, de Marinis F, Felip E, Goto Y, Liu G, et al. First-line Lorlatinib or Crizotinib in advanced ALK-positive lung Cancer. N Engl J Med. 2020;383:2018-29.

199. Garassino MC, Cho BC, Kim JH, Mazières J, Vansteenkiste J, Lena H, et al. Durvalumab as third-line or later treatment for advanced non-smallcell lung cancer (ATLANTIC): an open-label, single-arm, phase 2 study. Lancet Oncol. 2018;19:521-36.

200. Liu SY, Dong ZY, Wu SP, Xie Z, Yan LX, Li YF, et al. Clinical relevance of PD-L1 expression and CD8+T cells infiltration in patients with EGFR-mutated and ALK-rearranged lung cancer. Lung Cancer. 2018;125:86-92.

201. Hong S, Chen N, Fang W, Zhan J, Liu Q, Kang S, et al. Upregulation of PD-L1 by EML4-ALK fusion protein mediates the immune escape in ALK positive NSCLC: implication for optional anti-PD-1/PD-L1 immune therapy for ALK-TKIs sensitive and resistant NSCLC patients. Oncoimmunology. 2016;5:e1094598.

202. Petrazzuolo A, Perez-Lanzon M, Martins I, Liu P, Kepp O, Minard-Colin V, et al. Pharmacological inhibitors of anaplastic lymphoma kinase (ALK) induce immunogenic cell death through on-target effects. Cell Death Dis. 2021;12:713.

203. Spigel DR, Reynolds C, Waterhouse D, Garon EB, Chandler J, Babu S, et al. Phase $1 / 2$ study of the safety and tolerability of Nivolumab plus Crizotinib for the first-line treatment of anaplastic lymphoma kinase translocation - positive advanced non-small cell lung Cancer (CheckMate 370). J Thorac Oncol. 2018;13:682-8.

204. Patel SP, Pakkala S, Pennell NA, Reckamp KL, Lanzalone S, Polli A, et al. Phase Ib study of Crizotinib plus Pembrolizumab in patients with previously untreated advanced non-small cell lung Cancer with ALK translocation. Oncologist. 2020;25:562-e1012.

205. Kim D-W, Gadgeel SM, Gettinger SN, Riely GJ, Oxnard GR, Mekhail $T$, et al. Safety and clinical activity results from a phase Ib study of alectinib plus atezolizumab in ALK+ advanced NSCLC (aNSCLC). J Clin Oncol. 2018. https://doi.org/10.1200/JCO.2018.36.15_suppl.9009.

206. Shaw AT, Lee S-H, Ramalingam SS, Bauer TM, Boyer MJ, Costa EC, et al. Avelumab (anti-PD-L1) in combination with crizotinib or lorlatinib in patients with previously treated advanced NSCLC: phase $1 \mathrm{~b}$ results from JAVELIN lung 101. J Clin Oncol. 2018. https://doi.org/10.1200/JCO. 2018.36.15_suppl.9008.

207. Lin JJ, Chin E, Yeap BY, Ferris LA, Kamesan V, Lennes IT, et al. Increased hepatotoxicity associated with sequential immune checkpoint inhibitor and Crizotinib therapy in patients with non-small cell lung Cancer. J Thorac Oncol. 2019;14:135-40.

208. Hamarsheh S, Groß O, Brummer T, Zeiser R. Immune modulatory effects of oncogenic KRAS in cancer. Nat Commun. 2020;11:5439.

209. Roskoski R Jr. Blockade of mutant RAS oncogenic signaling with a special emphasis on KRAS. Pharmacol Res. 2021;172:105806.

210. Moore AR, Rosenberg SC, McCormick F, Malek S. RAS-targeted therapies: is the undruggable drugged? Nat Rev Drug Discov. 2020;19:533-52.

211. Dennison L, Mohan AA, Yarchoan M. Tumor and systemic Immunomodulatory effects of MEK inhibition. Curr Oncol Rep. 2021;23:23.

212. Nishida N. Role of oncogenic pathways on the Cancer immunosuppressive microenvironment and its clinical implications in hepatocellular carcinoma. Cancers (Basel). 2021;13:3666. 
213. Peng DH, Rodriguez BL, Diao L, Gaudreau PO, Padhye A, Konen JM, et al. Th17 cells contribute to combination MEK inhibitor and anti-PD-L1 therapy resistance in KRAS/p53 mutant lung cancers. Nat Commun. 2021;12:2606.

214. Loi S, Dushyanthen S, Beavis PA, Salgado R, Denkert C, Savas P, et al. RAS/MAPK activation is associated with reduced tumor-infiltrating lymphocytes in triple-negative breast Cancer: therapeutic cooperation between MEK and PD-1/PD-L1 immune checkpoint inhibitors. Clin Cancer Res. 2016:22:1499-509.

215. Hellmann MD, Kim TW, Lee CB, Goh BC, Miller WH Jr, Oh DY, et al. Phase Ib study of atezolizumab combined with cobimetinib in patients with solid tumors. Ann Oncol. 2019;30:1134-42.

216. Brufsky A, Kim SB, Zvirbule Ž, Eniu A, Mebis J, Sohn JH, et al. A phase II randomized trial of cobimetinib plus chemotherapy, with or without atezolizumab, as first-line treatment for patients with locally advanced or metastatic triple-negative breast cancer (COLET): primary analysis. Ann Oncol. 2021;32:652-60.

217. Eng C, Kim TW, Bendell J, Argilés G, Tebbutt NC, Di Bartolomeo M, et al. Atezolizumab with or without cobimetinib versus regorafenib in previously treated metastatic colorectal cancer (IMblaze370): a multicentre, open-label, phase 3, randomised, controlled trial. Lancet Oncol. 2019;20:849-61.

218. Meric-Bernstam F, Larkin J, Tabernero J, Bonini C. Enhancing antitumour efficacy with immunotherapy combinations. Lancet. 2021;397:1010-22.

219. Li A, Yi M, Qin S, Chu Q, Luo S, Wu K. Prospects for combining immune checkpoint blockade with PARP inhibition. J Hematol Oncol. 2019;12:98.

220. Aparicio T, Baer R, Gautier J. DNA double-strand break repair pathway choice and cancer. DNA Repair (Amst). 2014;19:169-75.

221. Chandrasekaran A, Elias KM. Synthetic lethality in ovarian Cancer. Mol Cancer Ther. 2021;20:2117-28.

222. Yi M, Dong B, Qin S, Chu Q, Wu K, Luo S. Advances and perspectives of PARP inhibitors. Exp Hematol Oncol. 2019;8:29.

223. Stewart RA, Pilié PG, Yap TA. Development of PARP and immune-checkpoint inhibitor combinations. Cancer Res. 2018;78:6717-25.

224. Pantelidou C, Sonzogni O, De Oliveria TM, Mehta AK, Kothari A, Wang $D$, et al. PARP inhibitor efficacy depends on CD8(+) T-cell recruitment via Intratumoral STING pathway activation in BRCA-deficient models of triple-negative breast Cancer. Cancer Discov. 2019;9:722-37.

225. Jiao S, Xia W, Yamaguchi H, Wei Y, Chen MK, Hsu JM, et al. PARP inhibitor Upregulates PD-L1 expression and enhances Cancer-associated immunosuppression. Clin Cancer Res. 2017;23:3711-20.

226. Friedlander M, Meniawy T, Markman B, Mileshkin L, Harnett P, Millward $M$, et al. Pamiparib in combination with tislelizumab in patients with advanced solid tumours: results from the dose-escalation stage of a multicentre, open-label, phase $1 \mathrm{a} / \mathrm{b}$ trial. Lancet Oncol. 2019;20:1306-15.

227. Ramalingam SS, Thara E, Awad MM, Dowlati A, Haque B, Stinchcombe $T E$, et al. JASPER: phase 2 trial of first-line niraparib plus pembrolizumab in patients with advanced non-small cell lung cancer. Cancer. 2021. https://doi.org/10.1002/cncr.33885.

228. Konstantinopoulos PA, Waggoner S, Vidal GA, Mita M, Moroney JW, Holloway R, et al. Single-arm phases 1 and 2 trial of Niraparib in combination with Pembrolizumab in patients with recurrent platinum-resistant ovarian carcinoma. JAMA Oncol. 2019;5:1141-9.

229. Drew Y, de Jonge M, Hong SH, Park YH, Wolfer A, Brown J, et al. An open-label, phase II basket study of olaparib and durvalumab (MEDIOLA): results in germline BRCA-mutated (gBRCAm) platinum-sensitive relapsed (PSR) ovarian cancer (OC). Gynecol Oncol. 2018;149:246-7.

230. Karzai F, Madan RA, Owens H, Couvillon A, Hankin A, Williams M, et al. A phase 2 study of olaparib and durvalumab in metastatic castrateresistant prostate cancer ( $\mathrm{mCRPC}$ ) in an unselected population. J Clin Oncol. 2018. https://doi.org/10.1200/JCO.2018.36.6_suppl.163.

231. Vinayak S, Tolaney SM, Schwartzberg LS, Mita MM, McCann GA-L, Tan AR, et al. TOPACIO/Keynote-162: Niraparib + pembrolizumab in patients (pts) with metastatic triple-negative breast cancer (TNBC), a phase 2 trial. J Clin Oncol. 2018. https://doi.org/10.1200/JCO.2018.36. 15_suppl.1011.

232. Yue $S$, Li Y, Chen X, Wang J, Li M, Chen Y, et al. FGFR-TKI resistance in cancer: current status and perspectives. J Hematol Oncol. 2021;14:23.
233. Liang Q, Wang J, Zhao L, Hou J, Hu Y, Shi J. Recent advances of dual FGFR inhibitors as a novel therapy for cancer. Eur J Med Chem. 2021:214:113205.

234. Palakurthi S, Kuraguchi M, Zacharek SJ, Zudaire E, Huang W, Bonal DM, et al. The combined effect of FGFR inhibition and PD-1 blockade promotes tumor-intrinsic induction of antitumor immunity. Cancer Immunol Res. 2019;7:1457-71.

235. Deng H, Kan A, Lyu N, Mu L, Han Y, Liu L, et al. Dual vascular endothelial growth factor receptor and fibroblast growth factor receptor inhibition elicits antitumor immunity and enhances programmed cell Death-1 checkpoint blockade in hepatocellular carcinoma. Liver Cancer. 2020;9:338-57.

236. Gutierrez M, Subbiah V, Nemunaitis JJ, Mettu NB, Papadopoulos KP, Barve MA, et al. Safety and efficacy of pemigatinib plus pembrolizumab combination therapy in patients (pts) with advanced malignancies: results from FIGHT-101, an open-label phase I/II study. J Clin Oncol. 2020. https://doi.org/10.1200/JCO.2020.38.15_suppl.3606.

237. Siefker-Radtke AO, Currie G, Abella E, Vaena DA, Kalebasty AR, Curigliano G, et al. FIERCE-22: clinical activity of vofatamab (V) a FGFR3 selective inhibitor in combination with pembrolizumab $(P)$ in WT metastatic urothelial carcinoma, preliminary analysis. J Clin Oncol. 2019. https:// doi.org/10.1200/JCO.2019.37.15_suppl.4511.

238. Fu J, Su X, Li Z, Deng L, Liu X, Feng X, et al. HGF/c-MET pathway in cancer: from molecular characterization to clinical evidence. Oncogene. 2021:40:4625-51.

239. Saigi M, Alburquerque-Bejar JJ, Mc Leer-Florin A, Pereira C, Pros E, Romero OA, et al. MET-oncogenic and JAK2-inactivating alterations are independent factors that affect regulation of PD-L1 expression in lung Cancer. Clin Cancer Res. 2018;24:4579-87.

240. Balan M, Mier y Teran E, Waaga-Gasser AM, Gasser M, Choueiri TK, Freeman $\mathrm{G}$, et al. Novel roles of c-met in the survival of renal cancer cells through the regulation of HO-1 and PD-L1 expression. J Biol Chem. 2015;290:8110-20.

241. Martin V, Chiriaco C, Modica C, Acquadro A, Cortese M, Galimi F, et al. Met inhibition revokes IFNY-induction of PD-1 ligands in MET-amplified tumours. Br J Cancer. 2019;120:527-36.

242. Rodriguez CS, Larkin J, Patel PM, Valderrama BP, Rodriguez-Vida A, Glen $\mathrm{H}$, et al. Clinical activity of durvalumab and savolitinib in MET-driven, metastatic papillary renal cancer. J Clin Oncol. 2021. https://doi.org/10. 1200/JCO.2021.39.15_suppl.4511.

243. Xu H, Yu S, Liu Q, Yuan X, Mani S, Pestell RG, et al. Recent advances of highly selective CDK4/6 inhibitors in breast cancer. J Hematol Oncol. 2017;10:97.

244. Lelliott EJ, McArthur GA, Oliaro J, Sheppard KE. Immunomodulatory effects of BRAF, MEK, and CDK4/6 inhibitors: implications for combining targeted therapy and immune checkpoint blockade for the treatment of melanoma. Front Immunol. 2021:12:661737.

245. Zhang QF, Li J, Jiang K, Wang R, Ge JL, Yang H, et al. CDK4/6 inhibition promotes immune infiltration in ovarian cancer and synergizes with PD-1 blockade in a B cell-dependent manner. Theranostics. 2020;10:10619-33.

246. Yu J, Yan J, Guo Q, Chi Z, Tang B, Zheng B, et al. Genetic aberrations in the CDK4 pathway are associated with innate resistance to PD-1 blockade in Chinese patients with non-cutaneous melanoma. Clin Cancer Res. 2019;25:6511-23.

247. Schaer DA, Beckmann RP, Dempsey JA, Huber L, Forest A, Amaladas N, et al. The CDK4/6 inhibitor Abemaciclib induces a T cell inflamed tumor microenvironment and enhances the efficacy of PD-L1 checkpoint blockade. Cell Rep. 2018;22:2978-94.

248. Deng J, Wang ES, Jenkins RW, Li S, Dries R, Yates K, et al. CDK4/6 inhibition augments antitumor immunity by enhancing T-cell activation. Cancer Discov. 2018;8:216-33.

249. Pujol J-L, Vansteenkiste JF, Paz-Ares LG, Gregorc V, Mazieres J, Awad $\mathrm{MM}$, et al. A phase Ib study of abemaciclib in combination with pembrolizumab for patients (pts) with stage IV Kirsten rat sarcoma mutant (KRAS-Mut) or squamous non-small cell lung cancer (NSCLC) (NCT02779751): interim results. J Clin Oncol. 2020. https://doi.org/10. 1200/JCO.2020.38.15_suppl.9562.

250. Song Z, Wang M, Ge Y, Chen XP, Xu Z, Sun Y, et al. Tyrosine phosphatase SHP2 inhibitors in tumor-targeted therapies. Acta Pharm Sin B. 2021:11:13-29. 
251. Song Y, Zhao M, Zhang H, Yu B. Double-edged roles of protein tyrosine phosphatase SHP2 in cancer and its inhibitors in clinical trials. Pharmacol Ther. 2021. https://doi.org/10.1016/j.pharmthera.2021.107966.

252. Wang Y, Mohseni M, Grauel A, Diez JE, Guan W, Liang S, et al. SHP2 blockade enhances anti-tumor immunity via tumor cell intrinsic and extrinsic mechanisms. Sci Rep. 2021;11:1399.

253. Chen D, Barsoumian HB, Yang L, Younes Al, Verma V, Hu Y, et al. SHP-2 and PD-L1 inhibition combined with radiotherapy enhances systemic antitumor effects in an anti-PD-1-resistant model of non-small cell lung Cancer. Cancer Immunol Res. 2020;8:883-94.

254. Zhao M, Guo W, Wu Y, Yang C, Zhong L, Deng G, et al. SHP2 inhibition triggers anti-tumor immunity and synergizes with PD-1 blockade. Acta Pharm Sin B. 2019:9:304-15.

255. Brana I, Shapiro G, Johnson ML, Yu HA, Robbrecht D, Tan DS-W, et al. Initial results from a dose finding study of TN0155, a SHP2 inhibitor, in adults with advanced solid tumors. J Clin Oncol. 2021. https://doi.org/ 10.1200/JCO.2021.39.15_suppl.3005.

256. Khoo LT, Chen LY. Role of the CGAS-STING pathway in cancer development and oncotherapeutic approaches. EMBO Rep. 2018;19:e46935.

257. Gao P, Ascano M, Wu Y, Barchet W, Gaffney BL, Zillinger T, et al. Cyclic $\left[\mathrm{G}\left(2^{\prime}, 5^{\prime}\right) \mathrm{pA}\left(3^{\prime}, 5^{\prime}\right) \mathrm{p}\right]$ is the metazoan second messenger produced by DNA-activated cyclic GMP-AMP synthase. Cell. 2013;153:1094-107.

258. Ablasser A, Goldeck M, Cavlar T, Deimling T, Witte G, Röhl I, et al. cGAS produces a $2^{\prime}-5^{\prime}$-linked cyclic dinucleotide second messenger that activates STING. Nature. 2013;498:380-4.

259. Jiang M, Chen P, Wang L, Li W, Chen B, Liu Y, et al. CGAS-STING, an important pathway in cancer immunotherapy. J Hematol Oncol. 2020;13:81.

260. Abe T, Barber GN. Cytosolic-DNA-mediated, STING-dependent proinflammatory gene induction necessitates canonical NF-KB activation through TBK1. J Virol. 2014;88:5328-41.

261. Fuertes MB, Woo SR, Burnett B, Fu YX, Gajewski TF. Type I interferon response and innate immune sensing of cancer. Trends Immunol. 2013;34:67-73.

262. Lara PN Jr, Douillard JY, Nakagawa K, von Pawel J, McKeage MJ, Albert I, et al. Randomized phase III placebo-controlled trial of carboplatin and paclitaxel with or without the vascular disrupting agent vadimezan (ASA404) in advanced non-small-cell lung cancer. J Clin Oncol. 2011;29:2965-71.

263. Shih AY, Damm-Ganamet KL, Mirzadegan T. Dynamic structural differences between human and mouse STING Lead to differing sensitivity to DMXAA. Biophys J. 2018;114:32-9.

264. Conlon J, Burdette DL, Sharma S, Bhat N, Thompson M, Jiang Z, et al. Mouse, but not human STING, binds and signals in response to the vascular disrupting agent 5,6-dimethylxanthenone-4-acetic acid. J Immunol. 2013;190:5216-25.

265. Burdette DL, Vance RE. STING and the innate immune response to nucleic acids in the cytosol. Nat Immunol. 2013;14:19-26.

266. Burdette DL, Monroe KM, Sotelo-Troha K, Iwig JS, Eckert B, Hyodo M, et al. STING is a direct innate immune sensor of cyclic di-GMP. Nature. 2011:478:515-8.

267. Corrales L, Glickman LH, McWhirter SM, Kanne DB, Sivick KE, Katibah GE, et al. Direct activation of STING in the tumor microenvironment leads to potent and systemic tumor regression and immunity. Cell Rep. 2015:11:1018-30.

268. Ramanjulu JM, Pesiridis GS, Yang J, Concha N, Singhaus R, Zhang SY, et al. Design of amidobenzimidazole STING receptor agonists with systemic activity. Nature. 2018;564:439-43.

269. Pan BS, Perera SA, Piesvaux JA, Presland JP, Schroeder GK, Cumming JN, et al. An orally available non-nucleotide STING agonist with antitumor activity. Science. 2020;369:eaba6098.

270. Lv M, Chen M, Zhang R, Zhang W, Wang C, Zhang Y, et al. Manganese is critical for antitumor immune responses via CGAS-STING and improves the efficacy of clinical immunotherapy. Cell Res. 2020;30:966-79.

271. Wang C, Guan Y, Lv M, Zhang R, Guo Z, Wei X, et al. Manganese increases the sensitivity of the CGAS-STING pathway for doublestranded DNA and is required for the host defense against DNA viruses. Immunity. 2018;48:675-87.e7.

272. Nakamura T, Sato T, Endo R, Sasaki S, Takahashi N, Sato Y, et al. STING agonist loaded lipid nanoparticles overcome anti-PD-1 resistance in melanoma lung metastasis via NK cell activation. J Immunother Cancer. 2021;9:e002852.

273. Yi M, Niu M, Zhang J, Li S, Zhu S, Yan Y, et al. Combine and conquer: manganese synergizing anti-TGF- $\beta / P D-L 1$ bispecific antibody YM101 to overcome immunotherapy resistance in non-inflamed cancers. J Hematol Oncol. 2021;14:146.

274. Song Y, Liu Y, Teo HY, Hanafi ZB, Mei Y, Zhu Y, et al. Manganese enhances the antitumor function of CD8(+) T cells by inducing type interferon production. Cell Mol Immunol. 2021;18:1571-4.

275. Meric-Bernstam F, Sandhu SK, Hamid O, Spreafico A, Kasper S, Dummer R, et al. Phase lb study of MIW815 (ADU-S100) in combination with spartalizumab (PDR001) in patients (pts) with advanced/metastatic solid tumors or lymphomas. J Clin Oncol. 2019. https://doi.org/ 10.1200/JCO.2019.37.15_suppl.2507.

276. Harrington KJ, Brody J, Ingham M, Strauss J, Cemerski S, Wang M, et al. Preliminary results of the first-in-human (FIH) study of MK-1454, an agonist of stimulator of interferon genes (STING), as monotherapy or in combination with pembrolizumab (pembro) in patients with advanced solid tumors or lymphomas. Ann Oncol. 2018. https://doi. org/10.1093/annonc/mdy424.015.

277. Kontermann RE. Dual targeting strategies with bispecific antibodies. MAbs. 2012:4:182-97.

278. Lan Y, Zhang D, Xu C, Hance KW, Marelli B, Qi J, et al. Enhanced preclinical antitumor activity of M7824, a bifunctional fusion protein simultaneously targeting PD-L1 and TGF- $\beta$. Sci Transl Med. 2018;10:eaan5488.

279. Yi M, Zhang J, Li A, Niu M, Yan Y, Jiao Y, et al. The construction, expression, and enhanced anti-tumor activity of YM101: a bispecific antibody simultaneously targeting TGF- $\beta$ and PD-L1. J Hematol Oncol. 2021;14:27.

280. Liu D, Gong J, Liu T, Li K, Yin X, Liu Y, et al. Phase 1 study of SHR-1701, a bifunctional fusion protein targeting PD-L1 and TGF- $\beta$, in patients with advanced solid tumors. J Clin Oncol. 2021. https://doi.org/10.1200/JCO. 2021.39.15_suppl.2503.

281. Jiang C, Zhang L, Xu X, Qi M, Zhang J, He S, et al. Engineering a smart agent for enhanced immunotherapy effect by simultaneously blocking PD-L1 and CTLA-4. Adv Sci (Weinh). 2021;8:e2102500.

282. Berezhnoy A, Sumrow BJ, Stahl K, Shah K, Liu D, Li J, et al. Development and preliminary clinical activity of PD-1-guided CTLA-4 blocking Bispecific DART molecule. Cell Rep Med. 2020;1:100163.

283. Dovedi SJ, Elder MJ, Yang C, Sitnikova SI, Irving L, Hansen A, et al. Design and efficacy of a monovalent Bispecific PD-1/CTLA4 antibody that enhances CTLA4 blockade on PD-1(+) activated T cells. Cancer Discov. 2021;11:1100-17.

284. Jiang H, Ni H, Zhang P, Guo X, Wu M, Shen H, et al. PD-L1/LAG-3 bispecific antibody enhances tumor-specific immunity. Oncoimmunology. 2021:10:1943180.

285. Catenacci DV, Rosales M, Chung HC, H HY, Shen L, Moehler M, et al. MAHOGANY: margetuximab combination in HER2 + unresectable/ metastatic gastric/gastroesophageal junction adenocarcinoma. Future Oncol. 2021;17:1155-64.

286. Hellmann MD, Bivi N, Calderon B, Shimizu T, Delafontaine B, Liu ZT, et al. Safety and immunogenicity of LY3415244, a Bispecific antibody against TIM-3 and PD-L1, in patients with advanced solid tumors. Clin Cancer Res. 2021;27:2773-81.

287. Ma L, Gai J, Qiao P, Li Y, Li X, Zhu M, et al. A novel bispecific nanobody with PD-L1/TIGIT dual immune checkpoint blockade. Biochem Biophys Res Commun. 2020;531:144-51.

288. Geuijen C, Tacken P, Wang LC, Klooster R, van Loo PF, Zhou J, et al. A human CD137×PD-L1 bispecific antibody promotes anti-tumor immunity via context-dependent $T$ cell costimulation and checkpoint blockade. Nat Commun. 2021:12:4445

289. Jeong S, Park E, Kim HD, Sung E, Kim H, Jeon J, et al. Novel anti-41BB $\times$ PD-L1 bispecific antibody augments anti-tumor immunity through tumor-directed T-cell activation and checkpoint blockade. J Immunother Cancer. 2021;9:e002428.

290. Zhai T, Wang C, Xu Y, Huang W, Yuan Z, Wang T, et al. Generation of a safe and efficacious llama single-domain antibody fragment $(\mathrm{vHH})$ targeting the membrane-proximal region of 4-1BB for engineering therapeutic bispecific antibodies for cancer. J Immunother Cancer. 2021:9:e002131. 
291. Vitale LA, He LZ, Thomas LJ, Wasiuk A, O'Neill T, Widger J, et al. Development of CDX-527: a bispecific antibody combining PD-1 blockade and CD27 costimulation for cancer immunotherapy. Cancer Immunol Immunother. 2020;69:2125-37.

292. Yuan Q, Liang Q, Sun Z, Yuan X, Hou W, Wang Y, et al. Development of bispecific anti-c-met/PD-1 diabodies for the treatment of solid tumors and the effect of c-met binding affinity on efficacy. Oncoimmunology. 2021;10:1914954.

293. Hou W, Yuan Q, Yuan X, Wang Y, Mo W, Wang H, et al. A novel tetravalent bispecific antibody targeting programmed death 1 and tyrosineprotein kinase met for treatment of gastric cancer. Investig New Drugs. 2019;37:876-89.

294. Wu Y, Yu M, Sun Z, Hou W, Wang Y, Yuan Q, et al. Generation and characterization of a Bispecific antibody targeting both PD-1 and c-MET. Protein Pept Lett. 2018;24:1105-12.

295. Sun ZJ, Wu Y, Hou WH, Wang YX, Yuan QY, Wang HJ, et al. A novel bispecific c-MET/PD-1 antibody with therapeutic potential in solid cancer. Oncotarget. 2017:8:29067-79.

296. Koopmans I, Hendriks D, Samplonius DF, van Ginkel RJ, Heskamp S, Wierstra PJ, et al. A novel bispecific antibody for EGFR-directed blockade of the PD-1/PD-L1 immune checkpoint. Oncoimmunology. 2018;7:e1466016.

297. Kotanides H, Li Y, Malabunga M, Carpenito C, Eastman SW, Shen Y, et al. Bispecific targeting of PD-1 and PD-L1 enhances T-cell activation and antitumor immunity. Cancer Immunol Res. 2020;8:1300-10.

298. Wang Y, Ni H, Zhou S, He K, Gao Y, Wu W, et al. Tumor-selective blockade of CD47 signaling with a CD47/PD-L1 bispecific antibody for enhanced anti-tumor activity and limited toxicity. Cancer Immunol Immunother. 2021;70:365-76.

299. Tauriello DVF, Palomo-Ponce S, Stork D, Berenguer-Llergo A, BadiaRamentol J, Iglesias M, et al. TGF $\beta$ drives immune evasion in genetically reconstituted colon cancer metastasis. Nature. 2018;554:538-43.

300. Mariathasan S, Turley SJ, Nickles D, Castiglioni A, Yuen K, Wang Y, et al. TGF $\beta$ attenuates tumour response to PD-L1 blockade by contributing to exclusion of T cells. Nature. 2018;554:544-8.

301. Chen X, Wang L, Li P, Song M, Qin G, Gao Q, et al. Dual TGF- $\beta$ and PD-1 blockade synergistically enhances MAGE-A3-specific CD8(+) T cell response in esophageal squamous cell carcinoma. Int J Cancer. 2018;143:2561-74.

302. Kim BG, Malek E, Choi SH, Ignatz-Hoover JJ, Driscoll JJ. Novel therapies emerging in oncology to target the TGF- $\beta$ pathway. J Hematol Oncol. 2021;14:55.

303. Strauss J, Heery CR, Schlom J, Madan RA, Cao L, Kang Z, et al. Phase I trial of M7824 (MSB0011359C), a Bifunctional fusion protein targeting PD-L1 and TGF $\beta$, in advanced solid tumors. Clin Cancer Res. 2018:24:1287-95.

304. Paz-Ares L, Kim TM, Vicente D, Felip E, Lee DH, Lee KH, et al. Bintrafusp Alfa, a Bifunctional fusion protein targeting TGF- $\beta$ and PD-L1, in second-line treatment of patients with NSCLC: results from an expansion cohort of a phase 1 trial. J Thorac Oncol. 2020;15:1210-22.

305. Herrera-Camacho I, Anaya-Ruiz M, Perez-Santos M, Millán-Pérez Peña L, Bandala C, Landeta G. Cancer immunotherapy using anti-TIM3/PD-1 bispecific antibody: a patent evaluation of EP3356411A1. Expert Opin Ther Pat. 2019;29:587-93.

306. Papaccio F, Della Corte CM, Viscardi G, Di Liello R, Esposito G, Sparano F, et al. HGF/MET and the immune system: relevance for Cancer immunotherapy. Int J Mol Sci. 2018;19:3595.

307. Pickard JM, Zeng MY, Caruso R, Núñez G. Gut microbiota: role in pathogen colonization, immune responses, and inflammatory disease. Immunol Rev. 2017;279:70-89.

308. Yi M, Yu S, Qin S, Liu Q, Xu H, Zhao W, et al. Gut microbiome modulates efficacy of immune checkpoint inhibitors. J Hematol Oncol. 2018;11:47.

309. Yu J, Sun H, Cao W, Han L, Song Y, Wan D, et al. Applications of gut microbiota in patients with hematopoietic stem-cell transplantation. Exp Hematol Oncol. 2020;9:35.

310. Lin D, Hu B, Li P, Zhao Y, Xu Y, Wu D. Roles of the intestinal microbiota and microbial metabolites in acute GVHD. Exp Hematol Oncol. 2021;10:49.

311. Routy B, Le Chatelier E, Derosa L, Duong CPM, Alou MT, Daillère R, et al. Gut microbiome influences efficacy of PD-1-based immunotherapy against epithelial tumors. Science. 2018;359:91-7.
312. Matson V, Fessler J, Bao R, Chongsuwat T, Zha Y, Alegre ML, et al. The commensal microbiome is associated with anti-PD-1 efficacy in metastatic melanoma patients. Science. 2018:359:104-8.

313. Yi M, Jiao D, Qin S, Chu Q, Li A, Wu K. Manipulating gut microbiota composition to enhance the therapeutic effect of Cancer immunotherapy. Integr Cancer Ther. 2019;18:1534735419876351.

314. Sivan A, Corrales L, Hubert N, Williams JB, Aquino-Michaels K, Earley ZM, et al. Commensal Bifidobacterium promotes antitumor immunity and facilitates anti-PD-L1 efficacy. Science. 2015;350:1084-9.

315. Gopalakrishnan V, Spencer CN, Nezi L, Reuben A, Andrews MC, Karpinets TV, et al. Gut microbiome modulates response to anti-PD-1 immunotherapy in melanoma patients. Science. 2018;359:97-103.

316. Huang J, Liu D, Wang Y, Liu L, Li J, Yuan J, et al. Ginseng polysaccharides alter the gut microbiota and kynurenine/tryptophan ratio, potentiating the antitumour effect of antiprogrammed cell death 1/programmed cell death ligand 1 (anti-PD-1/PD-L1) immunotherapy. Gut. 2021. https://doi.org/10.1136/gutjnl-2020-321031.

317. Baruch EN, Youngster I, Ben-Betzalel G, Ortenberg R, Lahat A, Katz L, et al. Fecal microbiota transplant promotes response in immunotherapy-refractory melanoma patients. Science. 2021;371:602-9.

318. Waldmann TA. Cytokines in Cancer immunotherapy. Cold Spring Harb Perspect Biol. 2018;10:a028472.

319. Robbins Y, Friedman J, Clavijo PE, Sievers C, Bai K, Donahue RN, et al. Dual PD-L1 and TGF-b blockade in patients with recurrent respiratory papillomatosis. J Immunother Cancer. 2021;9:e003113.

320. Tsukamoto H, Fujieda K, Miyashita A, Fukushima S, Ikeda T, Kubo Y, et al. Combined blockade of IL6 and PD-1/PD-L1 signaling abrogates mutual regulation of their immunosuppressive effects in the tumor microenvironment. Cancer Res. 2018;78:5011-22.

321. Diab A, Tannir NM, Bentebibel SE, Hwu P, Papadimitrakopoulou V, Haymaker C, et al. Bempegaldesleukin (NKTR-214) plus Nivolumab in patients with advanced solid tumors: phase I dose-escalation study of safety, efficacy, and immune activation (PIVOT-02). Cancer Discov. 2020;10:1158-73.

322. Naing A, Infante JR, Papadopoulos KP, Chan IH, Shen C, Ratti NP, et al. PEGylated IL-10 (Pegilodecakin) induces systemic immune activation, CD8(+) T cell invigoration and polyclonal T cell expansion in Cancer patients. Cancer Cell. 2018;34:775-91.e3.

323. Algazi AP, Twitty CG, Tsai KK, Le M, Pierce R, Browning E, et al. Phase II trial of IL-12 plasmid transfection and PD-1 blockade in immunologically quiescent melanoma. Clin Cancer Res. 2020;26:2827-37.

324. Wrangle JM, Velcheti V, Patel MR, Garrett-Mayer E, Hill EG, Ravenel JG, et al. ALT-803, an IL-15 superagonist, in combination with nivolumab in patients with metastatic non-small cell lung cancer: a non-randomised, open-label, phase 1b trial. Lancet Oncol. 2018;19:694-704.

325. Atkins MB, Hodi FS, Thompson JA, McDermott DF, Hwu WJ, Lawrence DP, et al. Pembrolizumab plus Pegylated interferon alfa- $2 \mathrm{~b}$ or Ipilimumab for advanced melanoma or renal cell carcinoma: dosefinding results from the phase Ib KEYNOTE-029 study. Clin Cancer Res. 2018;24:1805-15.

326. Kim K, Skora AD, Li Z, Liu Q, Tam AJ, Blosser RL, et al. Eradication of metastatic mouse cancers resistant to immune checkpoint blockade by suppression of myeloid-derived cells. Proc Natl Acad Sci U S A. 2014;111:11774-9.

327. Magner WJ, Kazim AL, Stewart C, Romano MA, Catalano G, Grande C, et al. Activation of MHC class I, II, and CD40 gene expression by histone deacetylase inhibitors. J Immunol. 2000;165:7017-24.

328. Khan AN, Magner WJ, Tomasi TB. An epigenetically altered tumor cell vaccine. Cancer Immunol Immunother. 2004;53:748-54.

329. Woods DM, Sodré AL, Villagra A, Sarnaik A, Sotomayor EM, Weber J. HDAC inhibition Upregulates PD-1 ligands in melanoma and augments immunotherapy with PD-1 blockade. Cancer Immunol Res. 2015;3:1375-85.

330. Truong AS, Zhou M, Krishnan B, Utsumi T, Manocha U, Stewart KG, et al. Entinostat induces antitumor immune responses through immune editing of tumor neoantigens. J Clin Invest. 2021;131:e138560.

331. Bissonnette RP, Cesario RM, Goodenow B, Shojaei F, Gillings M. The epigenetic immunomodulator, $\mathrm{HBI}-8000$, enhances the response and reverses resistance to checkpoint inhibitors. BMC Cancer. 2021;21:969. 
332. Ny L, Jespersen H, Karlsson J, Alsén S, Filges S, All-Eriksson C, et al. The PEMDAC phase 2 study of pembrolizumab and entinostat in patients with metastatic uveal melanoma. Nat Commun. 2021;12:5155.

333. Novitskiy SV, Ryzhov S, Zaynagetdinov R, Goldstein AE, Huang Y, Tikhomirov OY, et al. Adenosine receptors in regulation of dendritic cell differentiation and function. Blood. 2008;112:1822-31.

334. Kjaergaard J, Hatfield S, Jones G, Ohta A, Sitkovsky M. A(2A) adenosine receptor gene deletion or synthetic a(2A) antagonist liberate tumorreactive CD8(+) T cells from tumor-induced immunosuppression. J Immunol. 2018;201:782-91.

335. Borodovsky A, Barbon CM, Wang Y, Ye M, Prickett L, Chandra D, et al. Small molecule AZD4635 inhibitor of a(2A)R signaling rescues immune cell function including CD103(+) dendritic cells enhancing anti-tumor immunity. J Immunother Cancer. 2020;8:e000417.

336. Leone RD, Emens LA. Targeting adenosine for cancer immunotherapy. J Immunother Cancer. 2018;6:57.

337. Fong L, Hotson A, Powderly JD, Sznol M, Heist RS, Choueiri TK, et al. Adenosine $2 \mathrm{~A}$ receptor blockade as an immunotherapy for treatmentrefractory renal cell Cancer. Cancer Discov. 2020;10:40-53.

338. Varghese S, Pramanik S, Williams LJ, Hodges HR, Hudgens CW, Fischer GM, et al. The Glutaminase inhibitor CB-839 (Telaglenastat) enhances the Antimelanoma activity of T-cell-mediated immunotherapies. Mol Cancer Ther. 2021;20:500-11.

339. Yu S, Li A, Liu Q, LiT, Yuan X, Han X, et al. Chimeric antigen receptor T cells: a novel therapy for solid tumors. J Hematol Oncol. 2017;10:78.

340. Tian Y, Li Y, Shao Y, Zhang Y. Gene modification strategies for next-generation CART cells against solid cancers. J Hematol Oncol. 2020;13:54.

341. Grosser R, Cherkassky L, Chintala N, Adusumilli PS. Combination immunotherapy with CART cells and checkpoint blockade for the treatment of solid tumors. Cancer Cell. 2019;36:471-82.

342. Song Y, Liu Q, Zuo T, Wei G, Jiao S. Combined antitumor effects of antiEGFR variant III CAR-T cell therapy and PD-1 checkpoint blockade on glioblastoma in mouse model. Cell Immunol. 2020;352:104112.

343. Zah E, Nam E, Bhuvan V, Tran U, Ji BY, Gosliner SB, et al. Systematically optimized BCMA/CS1 bispecific CAR-T cells robustly control heterogeneous multiple myeloma. Nat Commun. 2020;11:2283.

344. Adusumilli PS, Zauderer MG, Rivière I, Solomon SB, Rusch VW, O'Cearbhaill RE, et al. A phase I trial of regional Mesothelin-targeted CART-cell therapy in patients with malignant pleural disease, in combination with the anti-PD-1 agent Pembrolizumab. Cancer Discov. 2021;11:2748-63.

345. Rafiq S, Yeku OO, Jackson HJ, Purdon TJ, van Leeuwen DG, Drakes DJ, et al. Targeted delivery of a PD-1-blocking scFv by CAR-T cells enhances anti-tumor efficacy in vivo. Nat Biotechnol. 2018;36:847-56.

346. Zhang T, Agarwal A, Almquist RG, Runyambo D, Park S, Bronson E, et al. Expression of immune checkpoints on circulating tumor cells in men with metastatic prostate cancer. Biomark Res. 2021;9:14.

\section{Publisher's Note}

Springer Nature remains neutral with regard to jurisdictional claims in published maps and institutional affiliations.

Ready to submit your research? Choose BMC and benefit from:

- fast, convenient online submission

- thorough peer review by experienced researchers in your field

- rapid publication on acceptance

- support for research data, including large and complex data types

- gold Open Access which fosters wider collaboration and increased citations

- maximum visibility for your research: over $100 \mathrm{M}$ website views per year

At BMC, research is always in progress.

Learn more biomedcentral.com/submissions 